\title{
Diversity of Micro-algae and Cyanobacteria on Building Facades and Monuments in India
}

\author{
Lakshmi Kumari Samad and Siba Prasad Adhikary* \\ P.G. Department of Botany and Biotechnology, Utkal University, Bhubaneswar - 751004, India
}

\begin{abstract}
Fifty seven taxa of Cyanobacteria and 15 taxa of Chlorophyta were recorded from the exterior of buildings and rock surfaces of monuments in different regions in India. Four cyanobacteria, e.g. Chroococcidiopsis kashayi, Pseudophormidium indicum, Plectonema puteale and Scytonema geitleri, and the green alga Trentepholia abietina var. tenue occur on the sub-aerial habitats throughout the year. In addition, five other green algae: Chlorococcum infusionum, Scenedesmus arcuatus, Trentepholia aurea, Gloeocystis polydermatica and Printzina effusa, and 18 other cyanobacteria taxa of the genera Chroococcus (5), Asterocapsa (1), Cyanosarcina (2), Gloeocapsa (7), Gloeothece (2) and Scytonema (1) occur on the sub-aerial surfaces enduring extreme temperature and desiccation during summer months of the tropics. During the rainy season, the warm and humid climatic regime coupled with availability of moisture supported an additional ten green algae and 29 cyanobacteria in eight and 17 genera, respectively. The green algal genera Klebsormidium, Stichococcus and Trebouxia, which are dominant in temperate regions, did not occur on the sub-aerial habitats in India, however, species of Gloeocapsa, Chroococcus, Chroococcidiopsis, Phormidium, Leptolyngbya, Nostoc, Scytonema, Chlorella and Trentepholia showed global occurrence in similar habitats.
\end{abstract}

Key Words: building facades, cyanobacteria, distribution, micro-algae, monuments

\section{INTRODUCTION}

Terrestrial algae have been reported - as biofilms on the exposed surfaces of solid substrata in almost all climatic zones (Tripathi et al. 1991; Ortega-Calvo et al. 1993; Gaylarde and Gaylarde 2000; Darienko and Hoffmann 2003; Noguerol-Seoane and Rifón-Lastra 2003; Rindi and Guiry 2004; Crispim et al. 2004, 2006; Rindi et al. 2005; Ortega-Morales et al. 2005; Uher et al. 2005; Peraza Zurita et al. 2005; Barberousse et al. 2006; Gaylarde et al. 2006; Rindi and López-Bautista 2007). These organisms grow as epiphytes on tree bark, as epiliths on rocks and stones, and also on anthropogenic surfaces such as facades, concrete floors of roofs and other artificial surfaces of buildings where they cause aesthetically unacceptable discolouration of the structures (Tomaselli et al. 2000; Videla et al. 2000; Crispim et al. 2006; Barberousse et al. 2007). Such growths are common in humid places on uneven surfaces such as holes, crevices and also on damp building walls due to leaking, roof guttering, inadequate drainage of flat areas or from adjacent water courses. The

*Corresponding author (adhikary2k@hotmail.com) growth is rarely uniform, frequently forming streaks that follow areas of dampness. In general, in temperate regions such as Northern Europe and Korea, eukaryotic green micro-algae (Chlorophyta) are the frequently occurring terrestrial forms (Videla et al. 2000; Darienko and Hoffmann 2003; Rindi and Guiry 2004; Klochkova and Kim 2005; Barberousse et al. 2006), whereas cyanobacteria dominate the sub-aerial surfaces in warm temperate to tropical regions (Videla et al. 2000; Crispim et al. 2003, 2004; Ortega-Morales et al. 2005). Colonization by communities of terrestrial cyanobacteria, green algae and other microorganisms are reported to accelerate weathering of their substrata (Kovácik 2000; Peraza Zurita et al. 2005). Though the immediate consequence of such algal growth is disfigurement, the microbial biocoenoses, including fungi and bacteria, develop on the surfaces by utilizing organic molecules formed by primary production. Such communities act as biodeteriogens of concrete, mortar and stones by producing organic and inorganic acids (Gaylarde and Morton 1999; Brehm et al. 2005). Though such problems are important in humid and tropical climates there has been little information on algal diversity and cyanobacteria colonizing building facades and archaeologically important monuments in 
Table 1. List of the sampling sites, voucher number and the nature of habitat

\begin{tabular}{|c|c|c|c|}
\hline Site & Voucher no. & Place of collection & Nature of the habitat \\
\hline 1. & 1260 & Utkal University Campus, Bhubaneswar, Orissa & Lime surfaces wall \\
\hline 2. & 1261 & Utkal University Campus, Bhubaneswar, Orissa & Cement surfaces \\
\hline 3. & 1262 & Hatigumpha cave, Khandagiri, Bhubaneswar, Orissa & Rock surfaces \\
\hline 4. & 1263 & Sarat, Mayurbhanj, Orissa & Cement surfaces \\
\hline 5. & 1264 & Sarat, Mayurbhanj, Orissa & Brick surfaces \\
\hline 6. & 1265 & Khandagiri cave, Bhubaneswar, Orissa & Rock surfaces \\
\hline 7. & 1267 & Shivsagar temple, Assam & Cement wall \\
\hline 8. & 1268 & Jorhat, Assam & Cement surfaces \\
\hline 9. & 1269 & Jorhat, Assam & Cement wall \\
\hline 10. & 1273 & Parasurameswar temple, Bhubaneswar, Orissa & Rock wall \\
\hline 11. & 1274 & Mukteswar temple, Bhubaneswar, Orissa & Crust on wall \\
\hline 12. & 1278 & Khandagiri cave, Bhubaneswar, Orissa & Rock surfaces \\
\hline 13. & 1279 & Utkal University Campus, Bhubaneswar, Orissa & Paint wall surfaces \\
\hline 14. & 1280 & Utkal University Campus, Bhubaneswar, Orissa & Yellowish paint wall surfaces \\
\hline 15. & 1283 & Utkal University Campus, Bhubaneswar, Orissa & Cement surfaces \\
\hline 16. & 1285 & Temple, Koraput, Orissa & Rock surfaces \\
\hline 17. & 1287 & Parasurameswar temple, Bhubaneswar, Orissa & Wetted rocky wall \\
\hline 18. & 1288 & Bhaskareswar temple, Bhubaneswar, Orissa & Rock surfaces \\
\hline 19. & 1289 & Bhaskareswar temple, Bhubaneswar, Orissa & Crust on wall surfaces \\
\hline 20. & 1290 & Bhaskareswar temple, Bhubaneswar, Orissa & Limestone \\
\hline 21. & 1292 & Khandagiri cave, Bhubaneswar, Orissa & Rock surfaces \\
\hline 22. & 1294 & Khandagiri cave, Bhubaneswar, Orissa & Rock surfaces \\
\hline 23. & 1296 & Talopadeswar temple, Vanivihar, Bhubaneswar, Orissa & Cement wall \\
\hline 24. & 1297 & Gandhi park, Jaydev vihar, Bhubaneswar, Orissa & Cement wall \\
\hline 25. & 1298 & Utkal University Campus, Bhubaneswar, Orissa & Lime washed cement surfaces \\
\hline 26. & 1299 & Utkal University Campus, Bhubaneswar, Orissa & Wall surfaces \\
\hline 27. & 1302 & Saheed Nagar, Bhubaneswar, Orissa & Lime washed wall \\
\hline 28. & 1303 & Utkal University Campus, Bhubaneswar, Orissa & Lime washed wall \\
\hline 29. & 1304 & Maniakati, Ganjam, Orissa & Roof surfaces \\
\hline 30. & 1305 & Athagarh, Ganjam, Orissa & Lime coating surfaces \\
\hline 31. & 1306 & Unit - III, Rajmahal square, Bhubaneswar, Orissa & Painted wall \\
\hline 32. & 1307 & Unit - III, Rajmahal square, Bhubaneswar, Orissa & Cement wall \\
\hline 33. & 1308 & Baramunda, Bhubaneswar, Orissa & Cement surfaces \\
\hline 34. & 1309 & Jaydev vihar, Bhubaneswar, Orissa & Lime washed wall \\
\hline 35. & 1310 & Rasulgarh, Bhubaneswar, Orissa & Lime washed wall \\
\hline 36. & 1317 & Jaydev vihar, Bhubaneswar, Orissa & Lime washed wall \\
\hline 37. & 1318 & Utkal University Campus, Bhubaneswar, Orissa & Roof floor \\
\hline 38. & 1319 & AG old colony, Jaydev vihar, Bhubaneswar, Orissa & Water leakage wall \\
\hline 39. & 1323 & Utkal University Campus, Bhubaneswar, Orissa & Wall surfaces \\
\hline 40. & 1325 & Utkal University Campus, Bhubaneswar, Orissa & Wall surfaces \\
\hline 41. & 1326 & Baripada, Mayurbhanj, Orissa & Cement tile surfaces \\
\hline 42. & 1248 & Maplong Dam, Shillong, Meghalaya & Rock surface \\
\hline 43. & 1249 & Quarry, Shillong, Meghalaya & Limestone \\
\hline 44. & 1312 & Fort, Nahargarh, Jaipur, Rajasthan & Building wall \\
\hline 45. & 1313 & Fort (bottom floor), Nahargarh Jaipur, Rajasthan & Building wall \\
\hline 46. & 1314 & Fort, Nahargarh, Jaipur, Rajasthan & Mortar paste \\
\hline 47. & 1315 & Puskar, Rajasthan & Wall surface \\
\hline
\end{tabular}

India (Tripathi 1984; Tripathy et al. 1999; Pattanaik and Adhikary 2002). Here we report the cyanobacteria and micro-algal forms occurring on the exposed surfaces on rocky walls and buildings from various regions of India during the hot summer and after the monsoon rains.

\section{MATERIALS AND METHODS}

One hundred and eight crust samples were collected from 47 sub-aerial sites including new and old building 
facades and monuments. Substrata included limestone, sandstone, cement, concrete, brick, rock and lime washed building surfaces during monsoon, post monsoon and summer seasons. Sampling was carried out by gentle scraping with a sterile blade and needle, and the resulting material was stored in screw-cap specimen bottles. Each specimen was given a voucher number and stored in desiccated state at Utkal University, Bhubaneswar (Table 1). The crusts were soaked with sterile distilled water for 12-24 h, and examined for the presence of algae. A pinch of crust material was transferred to BG - 11 medium with or without combined nitrogen (Rippka et al. 1979) and to agar plates $(1.1 \% \mathrm{w} / \mathrm{v}$ agar in the same medium) and incubated at $28 \pm 1{ }^{\circ} \mathrm{C}$ under continuous light for up to 15 days. Photomicrographs of the organisms appearing in the cultures were taken using a Meiji trinocular research microscope fitted with a Nikon Coolpix 4500 digital camera. The organisms were identified based on the following monographs: West and West (1905), Tilden (1910), Thompson (1959), Desikachary (1959), Philipose (1967), Hindák (1977), Komárek and Fott (1983), Krishnamurthy (1998), Ortega-Calvo et al. (1993), Branco and Júnior (1996), Aboal et al. (2003), Mishra and Srivastava (2003), Uher et al. (2005), Rindi et al. (2005), Barberousse et al. (2006) and Gaylarde et al. $(2004,2006)$.

\section{RESULTS}

A total of 57 taxa of Cyanobacteria belonging to 23 genera and 15 taxa of Chlorophyta representing ten genera were recorded from the exteriors of buildings, tree trunks and exposed rock surfaces of monuments in different regions of India. A description of each of these organisms is presented. Voucher number, date of collection, place of collection and nature of the habitat of their occurrence is also given.

\section{Chlorophyta}

Class: Chlorophyceae

Order: Chlorococcales

Family: Chlorococcaceae

\section{Genus: Chlorococcum Meneghini}

1. Chlorococcum infusionum (Schrank) Meneghini (Pl. 1, Fig. 1)

[Synonym: Chlorococcum humicola (Nägeli) Rabenhorst 1868]

(Basionym: Cystococcus humicola Nägeli)

Komárek and Fott, 1983, p. 36, fig. 3; Philipose, 1967, p.
72, pl. 74, fig. 3b.

Cells spherical, light green in color, solitary or a number of cells crowded together to form a stratum; chloroplast with a hallow sphere with a lateral notch; cells 7-20 $\mu$ m diameter.

Occurred as greenish crust on a cement wall, Jorhat, Assam; Voucher no. 1269; Date of collection: 24/02/2007.

\section{Genus: Coenochloris Korshikov}

2. Coenochloris pyrenoidosa Koršikov (Pl. 1, Fig. 5)

Hindák, 1977, p. 19, pl. 3

Cell spherical; one parietal and cup shaped chloroplast with one pyrenoid; cell 3.6-4.0 $\mu \mathrm{m}$ diameter.

Occurred as greenish crust on lime washed wall surfaces, Jaydev vihar, Bhubaneswar, Orissa; Voucher no. 1309; Date of collection: 14/08/2007.

\section{Genus: Bracteacoccus Tereg}

3. Bracteacoccus minor (Chodat) Petrová (Pl. 1, Figs 2-3)

[Synonym: Botrydiopsis minor Chodat 1913]

(Basionym: Botrydiopsis minor Chodat)

Komárek and Fott, 1983, p. 136, pl. 37, figs 2a-d; Barberousse et al. 2006, p. 88 fig. 1. 48.

Cells spherical, single or in group; globose; polygonal parietal chloroplasts many, without pyrenoid; 6.8-23.0 $\mu$ m diameter.

Occurred as greenish crust on lime washed wall surfaces, Jaydev vihar, Bhubaneswar, Orissa; Voucher no. 1317; Date of collection: 14/08/2007.

Reported from limestone, ceramics and brick surface of cultural monument, Ukraine (Darienko and Hoffmann, 2003); bed rock surface, Great Smoky Mountain, USA (Gomez et al., 2003).

\section{Genus: Radiococcus Schmidle}

4. Radiococcus nimbatus (De Wildmann) Schmidle (Pl. 1, Fig. 4)

[Synonym: Pleurococcus nimbatus De Wildman]

(Basionym: Pleurococcus nimbatus De Wildman)

Komárek and Fott, 1983, p. 399, pl. 120, fig. 3; Thompson, 1959, P. 137, fig. 6. 155.

Colonies 4 celled, 14-20 $\mu \mathrm{m}$ diameter; chloroplast single, parietal without pyrenoid; cells more or less pyramidal and angular remaining in a group; cell 5-12 $\mu \mathrm{m}$ diameter.

Occurred as greenish crust on lime washed wall surfaces, Jaydev vihar, Bhubaneswar, Orissa; Voucher no. 1317; Date of collection: 14/08/2007. 


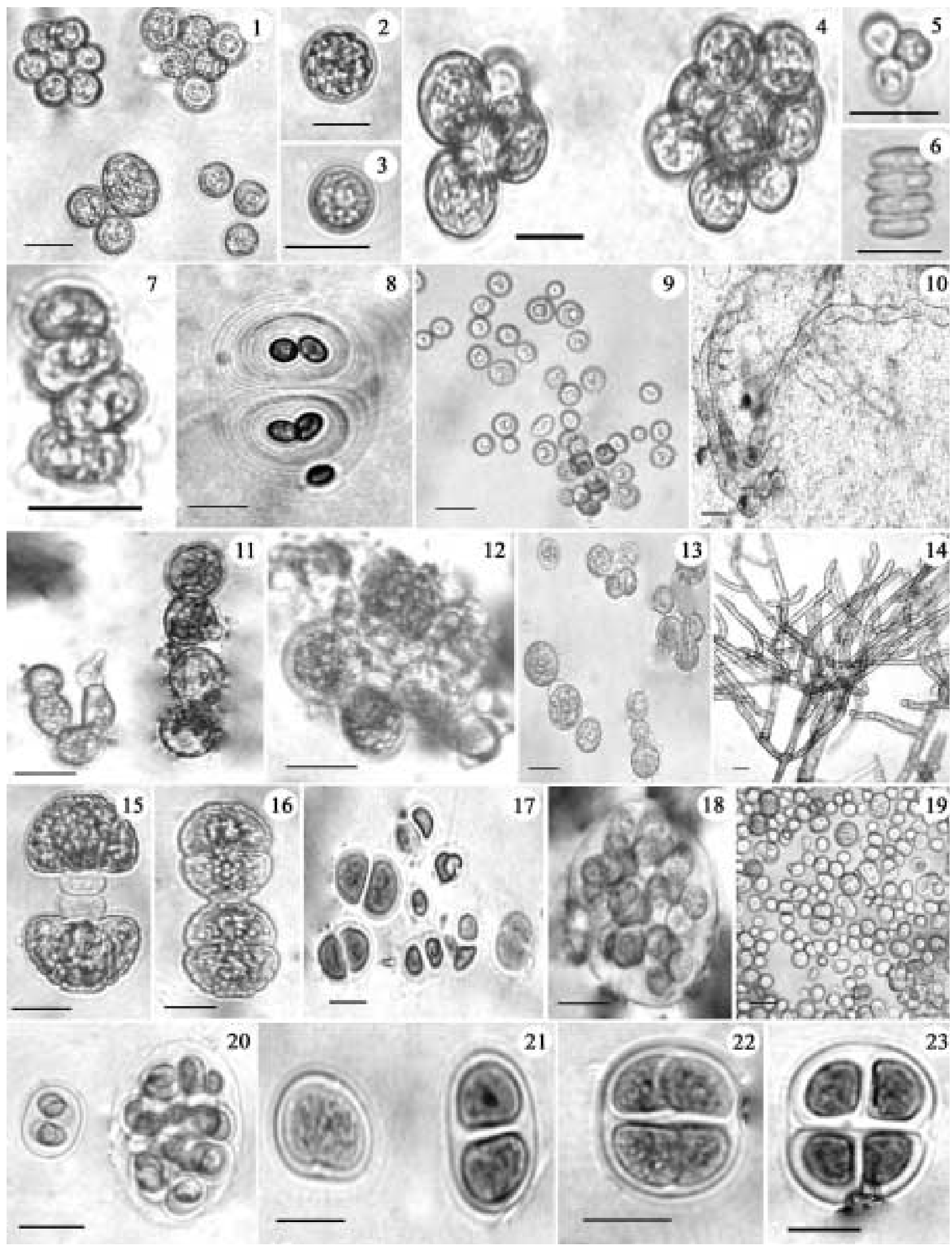

Plate 1. Fig. 1. Chlorococcum infusionum, Figs 2-3. Bracteacoccus minor, Fig. 4. Radiococcus nimbatus, Fig. 5. Coenochloris pyrenoidosa, Fig. 6. Scenedesmus bijugatus var. bicellularis, Fig. 7. Scenedesmus arcuatus, Fig. 8. Gloeocystis polydermatica, Fig. 9. Chlorella vulgaris, Fig. 10. Trentepohlia aurea, Fig. 11. Trentepohlia abietina var. tenue, Fig. 12. Trentepohlia rigidula, Fig. 13. Trentepohlia umbrina, Fig. 14. Printzina effusa, Fig. 15. Cosmarium misellum, Fig. 16. Cosmarium nitidulum, Fig. 17. Chroococcus indicus, Fig. 18. Chroococcus limneticus, Fig. 19. Cyanosarcina burmensis, Fig. 20. Chroococcus lithophilus, Figs 21-23. Chroococcus minor (Fig. 21. Showing colony forms of initial stages, Figs 22-23. Cell division and colony formation). Scale bar: Figs 1-23 $=10 \mu \mathrm{m}$. 
Family: Scenedesmaceae

\section{Genus: Scenedesmus Meyen}

5. Scenedesmus arcuatus (Lemmermann) (Pl. 1, Fig.7)

[Synonym: Scenedesmus bijugus var. arcuatus Lemmermann; Scenedesmus bijugatus f. arcuatus Lemmermann]

Philipose, 1967, p. 256, pl. 258, fig. 166 (b).

Colonies 4 or 16 celled, curved, cell oblong or ovoid, cells wall smooth, cells 5.0-7.5 $\mu \mathrm{m}$ broad, 9.9-12.0 $\mu \mathrm{m}$ long.

Occurred as greenish crust on cement walls, Jorhat, Assam; Voucher no. 1269; Date of collection: 24/02/2007.

6. Scenedesmus bijugatus Kützing var. bicellularis Chodat (Pl. 1, Fig. 6)

Philipose, 1967, P. 253, fig. 164, fig. 7d.

Colonies flat, 2-4-8 celled, arranged in a single linear series, cell oblong - ellipsoidal to ovoid with the ends broadly rounded, 2.6-3.5 $\mu \mathrm{m}$ broad, 6-11 $\mu \mathrm{m}$ long.

Occurred as greenish crust on cement walls, Gandhi park, Bhubaneswar, Orissa; Voucher no. 1297;

Date of collection: 19/08/2007.

Order: Tetrasporales

Family: Gloeocystaceae

\section{Genus: Gloeocystis Nägeli}

7. Gloeocystis polydermatica (Kützing) Hindák (Pl. 1, Fig. 8)

[Synonym: Gleocapsa polydermatica Kützing 1846]

Desikachary, 1959, p. 115, pl. 25, fig. 1.

Cells spherical, without sheath 3.0-4.0 $\mu \mathrm{m}$ diameter, blue green; sheath colorless, very thick, distinctly lamellated.

Occurred as blackish crust on rock surface of Khandagiri cave, Bhubaneswar, Orissa; Voucher no. 1294; Date of collection: 17/04/2007.

Reported from window shade, Varanasi, India (Tripathi, 1984).

Class: Trebouxiophyceae

Order: Chlorellales

Family: Chlorellaceae

\section{Genus: Chlorella Beijerinck}

8. Chlorella vulgaris Beijerinck (Pl. 1, Fig. 9)

[Synonym: Chlorella pyrenoidosa var. duplex (Kützing) West; Pleurococcus beijerinckii Artari 1892; Chlorella communis Artari 1906; Chlorella vulgaris var. viridis Chodat 1913; Chlorella terricola Gollerbach 1936; Chlorella Candida Shihira \& Krauss 1965]

Komárek and Fott, 1983, p. 594, pl. 168, fig. 2;
Philipose, 1967, p. 173, pl. 174, fig. 82d.

Cells spherical; one parietal and cupshaped chloroplast with one pyrenoid; cells 7.5-10.0 $\mu \mathrm{m}$ diameter.

Occurred as greenish crust on cement wall, Jorhat, Assam; Voucher no. 1269; Date of collection: 24/02/2007.

Reported from ceramics and white washing surfaces of cultural monument, Ukraine (Darienko and Hoffmann, 2003); Urban wall, Europe (Rindi and Guiry, 2004); building stone, Salamanca and Toledo, Spain (OrtegaCalvo et al., 1993).

Class: Ulvophyceae

Order: Trentepohliales

Family: Trentepohliaceae

\section{Genus: Trentepohlia Martius}

9. Trentepohlia aurea (Linneus) Martius (Pl. 1, Fig. 10)

[Synonym: Byssus cryptarum Linnaeus 1753; Byssus aurea Linnaeus 1759; Chroolepus aureum Kützing 1843; Chroolepus oleiferum Kützing 1843; Chroolepus aureus var. tomentosus Kützing 1845; Chroolepus aureus var. pulvinatus Kützing 1845; Chroolepus aureus var. glomeratus Kützing 1845; Chroolepus aureus var. incrassatus Kützing 1845; Chroolepus aureus var. alpinus Kützing 1845; Chroolepus velutinum Kützing 1845; Trentepohlia capitellata Ripart 1876; Trentepohlia velutina (Kützing) Hansgirg 1886; Trentepohlia maxima Karsten 1891; Trentepohlia germanica Glück 1896; Trentepohlia gobii Meyer 1936]

(Basionym: Byssus aurea Linnaeus)

Krishnamurthy, 1998, p. 186, pl. 152, fig. 29a.

Filament well branched, yellowish - green; cells cylindrical, slightly inflated, 8-10 $\mu \mathrm{m}$ broad and 20-22 $\mu \mathrm{m}$ long; several chloroplast, discoid; apical cell obtuse.

Occurred as greenish crust on cement walls, Shivsagar temple, Assam; Voucher no. 1267; Date of collection: 24/02/2007.

10. Trentepohlia abietina var. tenue (Zeller) Cribb (Pl. 1, Fig. 11)

[Synonym: Trentepohlia tenuis (Zeller) de Toni 1889]

(Basionym: Chroolepus tenue Zeller)

Krishnamurthy, 1998, p. 191, pl. 29, fig. 29 f.

Cells elongate - ellipsoidal, sub - cylindrical, 6-8 $\mu \mathrm{m}$ broad and 8-14 $\mu \mathrm{m}$ long.

Occurred as pinkish paint surface of building wall, Department of Botany, Utkal University, Bhubaneswar, Orissa; Voucher no. 1279; Date of collection: 25/05/2007.

11. Trentepohlia rigidula (Müller) Hariot (Pl. 1, Fig. 12)

[Synonym: Trentepohlia monilia de Wildeman 1891] 
Krishnamurthy, 1998, p. 189, fig. 29: I. J, pl. 1, fig. 4.

Thallus dark green; filament differentiated into prostrate and erect system; cells of erect system barrel shaped, less deeply constricted, 23-33 $\mu \mathrm{m}$ long. 15-20 $\mu \mathrm{m}$ broad.

Occurred as greenish crust on cement walls, Talapadeswar temple, Utkal University campus, Bhubaneswar, Orissa; Voucher no. 1296; Date of collection: 16/08/2007.

12. Trentepohlia umbrina (Kützing) Bornet in Wille (Pl. 1, Fig. 13)

[Synonym: Trentepohlia odorata var. umbrina (Kützing) Hariot; Chroolepus umbrinum Kützing 1843; Phycopeltis umbrina (Kützing) Thompson and Wujek 1997]

(Basionym: Chroolepus umbrinum Kützing)

Krishnamurthy, 1998, p. 190; Gaylarde et al. 2006, p. 120, fig. 2.

Filaments form a thin, crustaceous and fairly granular layer, reddish - brown; cell of prostrate system rounded or ellipsoid, separating from one another, 13-20 $\mu \mathrm{m}$ diameter with smooth wall; sporangia stalked, terminal, erect filaments.

Occurred as greenish crust on cement walls, Gandhi park, Bhubaneswar, Orissa; Voucher no. 1297; Date of collection: 19/08/2007.

Reported from limestone, Historic building, Mayan site of Edzna, Campeche, Mexico (Gaylarde et al. 2006); painted cement of cottage, Waipio valley, Hawaii Island (Rindi et al. 2005).

\section{Genus: Printzina Thompson and Wujek}

13. Printzina effusa (Krempelhüber) Thompson and Wujek (Pl. 1, Fig. 14)

[Synonym: Coenogonium effusum Krempelhüber 1876; Trentepohlia effusa (Krempelhüber) Hariot 1889; Trentepohlia setifera (Farlow) Hariot 1889]

(Basionym: Coenogonium effusum Krempelhüber)

Rindi et al., 2005, p. 273-276, figs 13-22.

Filament prostrate or erect, abundantly branched, irregular; cell elliptical or cylindrical, 6-9 $\mu \mathrm{m}$ wide in upper parts, $9-12 \mu \mathrm{m}$ in the lower parts, 2 to 3 times longer than wide.

Occurred as greenish crust on cement surface of building wall, Jorhat, Assam; Voucher no. 1268; Date of collection: 25/02/2007.

Reported from bark of a tree, Makiki valley, Oahu (Rindi et al. 2005).

Class: Zygnematophyceae
Order: Zygnematales

Family: Desmidiaceae

\section{Genus: Cosmarium Ralfs}

14. Cosmarium misellum Skuja (Pl. 1, Fig. 15)

Mishra and Srivastava, 2003, p. 87. pl. 2, figs $3 \& 22$.

Cell solitary, green; deeply constricted sinus, narrowly linear; semi cells broad at base, slightly less broad at apex, apex slightly compressed; cell wall smooth; showed enlarged cell in dividing stage; cells 140-155 $\mu \mathrm{m}$ broad and 268-280 $\mu \mathrm{m}$ long; isthmus constricted, $80 \mu \mathrm{m}$ broad and $123 \mu \mathrm{m}$ long.

Occurred as greenish crust on water leakage walls, AG old colony, Jeydev vihar, Bhubaneswar, Orissa; Voucher no. 1319; Date of collection: 19/10/2007.

\section{Cosmarium nitidulum De Notaris (Pl. 1, Fig. 16)}

West \& West, 1905, p. 197, pl. 64, figs 1-3.

Cell solitary, longer than broad; sinus less deep and closed, linear; semicells semicircular; cell wall crenulate; apex round or slight straight; cells $28-29 \mu \mathrm{m}$ broad and 32-33 $\mu \mathrm{m}$ long; isthmus 6-7 $\mu \mathrm{m}$ broad.

Occurred as greenish crust on water leakage walls, AG old colony, Jeydev vihar, Bhubaneswar; Orissa; Voucher no. 1319; Date of collection: 19/10/2007.

\section{Cyanophyta (Cyanobacteria)}

Class: Cyanophyceae

Order: Chroococcales

Family: Chroococcaceae

\section{Genus: Chroococcus Nägeli}

16. Chroococcus indicus Zeller (Pl. 1, Fig. 17)

Desikachary, 1959, p. 107, pl. 26, fig. 5.

Thallus gelatinous, thin, pale brownish; cells single, oblong to sub-spherical, 3.5-7.5 $\mu \mathrm{m}$ in diameter, sheath hyaline.

Occurred as blackish crust on cement wall surface, Sarat, Mayurbhanj, Orissa; Voucher no. 1263; Date of collection: 24/04/2007.

Reported from roof top, Varanasi, India (Tripathi, 1984).

17. Chroococcus limneticus Lemmermann (Pl. 1, Fig. 18)

[Synonym: Chroococcus limneticus var. carneus (Chodat) Lemmermann 1904; Gloeocapsa limnetica (Lemmermann) Hollerbach 1938; Anacystis limnetica (Lemmermann) Drouet and Daily 1952; Anacystis thermalis f. major (Lagerheim) Drouet and Daily 1956]

Desikachary, 1959, p. 107, pl. 26, fig. 2.

Cells spherical, surrounded by individual mucilagi- 
nous envelope, embedded in colorless and spherical gelatinous slime; 4.5-5.5 $\mu \mathrm{m}$ diameter.

Occurred as blackish crust on cement wall surface, Sarat, Mayurbhanj, Orissa; Voucher no.1263; Date of collection: 26/04/2007.

Reported from building facades, France (Barberousse et al., 2006).

18. Chroococcus lithophilus Ercegović (Pl. 1, Fig. 20)

Barberousse et al., 2006, p. 94 fig. 26, 67.

Cells spherical, hemispherical after division, surrounded by a thin, colorless to yellowish brown sheath; $4-8 \mu \mathrm{m}$ diameter.

Occurred as greenish crust on lime surface of building wall; Utkal University campus, Bhubaneswar, Orissa; Voucher no. 1260; Date of collection: 02/03/2007.

Reported from building wall of Nosa Señora da Esclavitude, Galicia, Spain (Noguerol-Seoane and RefónLastra, 2003); building façade, France (Barberousse et al., 2006).

19. Chroococcus minor (Kützing) Nägeli (Pl. 1, Figs 2123)

[Synonym: Protococcus minor Kützing 1845; Pleurococcus minor (Kützing) Rabenhorst 1863]

(Basionym: Protococcus minor Kützing)

Desikachary, 1959, p. 105, pl. 26, fig. 4, 15.

Thallus slimy, gelatinous, dirty blue-green, cells spherical or hemispherical, 3-4 $\mu \mathrm{m}$ diameter; singly or in pairs; sheath colorless, very thin, hardly visible.

Occurred as greenish crust on lime surface of building wall; Utkal University campus, Bhubaneswar, Orissa; Voucher no. 1260; Date of collection: 02/03/2007.

20. Chroococcus pallidus (Nägeli) Nägeli (Pl. 2, Fig. 24)

Desikachary, 1959, p. 109, pl. 26, fig. 5.

Colonies with 2-8 or 16 cells when overlap; cells spherical or ellipsoidal, 4.2-6.0 $\mu \mathrm{m}$ diameter; sheath thick; with sheath 5-10 $\mu \mathrm{m}$ broad and without sheath $5-7 \mu \mathrm{m}$ broad.

Occurred as brownish crust on cement wall, unit - 3, Bhubaneswar, Orissa; Voucher no. 1307; Date of collection: 12/10/2007.

Reported from bedrock surface, Great Smoky Mountain, USA (Gomez et al., 2003).

21. Chroococcus schizodermaticus West and West (Pl. 2, Figs 25-26)

Desikachary, 1959, p. 103, pl. 26, fig. 17.

Thallus globose or triangular, sometimes kidney - shaped, associated in colonies of two or three; colonies solitary or in small groups; sheath very thick, straw coloured or dark coloured, strongly lamellated, finally and irregularly peeling off; cell 5-9 $\mu \mathrm{m}$ in diameter; cells somewhat thick; content granular, bluish green.

Occurred as greenish crust on lime surface of building wall; Utkal University campus, Bhubaneswar, Orissa; Voucher no. 1260; Date of collection: 02/03/2007.

22. Chroococcus varius A. Braun in Rabenhorst (Pl. 2, Fig. 27)

Desikachary, 1959, p. 108, pl. 24, fig. 5.

Cells spherical, $2-3 \mu \mathrm{m}$ in diameter, grouped in a small number of coenobia, mucilaginous sheath, multilayered, occasionally indistinct.

Occurred as greenish crust on lime surface of building wall; Utkal University campus, Bhubaneswar, Orissa; Voucher no. 1260; Date of collection: 02/03/2007.

\section{Genus: Asterocapsa Chu}

23. Asterocapsa divina Komárek (Pl. 2, Fig. 28)

Aboal et al., 2003, p. 59, figs 3-8.

Cells spherical, yellowish-green to bluish green in colour enveloped by thick or firm granular sheath, sheath coloured, filaments $14.4-16.8 \mu \mathrm{m}$ broad with sheath; cell 6.0-9.6 $\mu \mathrm{m}$ broad and 12.0-13.5 $\mu \mathrm{m}$ long.

Occurred as blackish crust on cement surface of boundary wall; Utkal University campus, Bhubaneswar, Orissa; Voucher no. 1283; Date of collection: 02/03/2007.

Reported from lime stone rock cave, South Eastern, Spain (Aboal et al., 2003).

Family: Xenococcaceae

\section{Genus: Cyanosarcina Kovácik}

24. Cyanosarcina burmensis (Skuja) Kovácik (Pl. 1, Fig. 19)

[Synonym: Myxosarcina burmensis Skuja 1949]

Desikachary, 1959, p. 178, pl. 32, figs 20-22.

Colonies gelatinous, cells spherical or ellipsoidal, closely arranged to form colonies in transverse or vertical series, pale blue green, homogeneous, individual sheath very thin, colonial mucilage colourless; cells $2.0-3.8 \mu \mathrm{m}$ diameter.

Occurred as greenish crust on building wall, Nahargarh fort, Jaipur, Rajasthan; Voucher no. 1313; Date of collection: 25/10/2007.

25. Cyanosarcina parthenonensis Anagnostidis (Pl. 2, Fig. 29) 


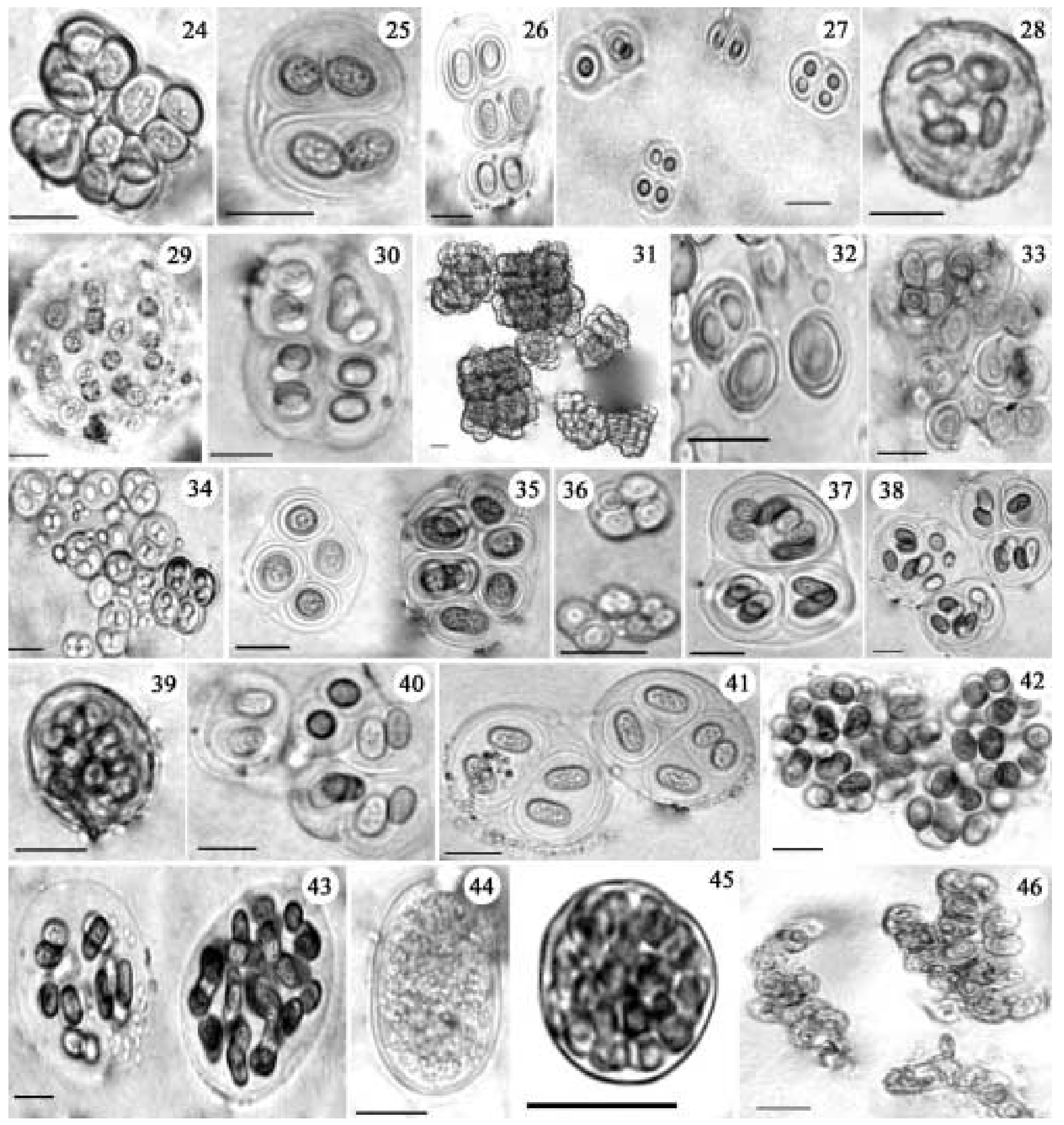

Plate 2. Fig. 24. Chroococcus pallidus, Figs 25-26. Chroococcus schizodermaticus (Fig. 25. young cell in colony, Fig. 26. colonies showing outer sheath layer often broken), Fig. 27. Chroococcus varius, Fig. 28. Asterocapsa divina, Fig. 29. Cyanosarcina parthenonsis, Fig. 30. Cyanosarcina spectabilis, Fig. 31. Gloeocapsopsis crepidinum, Fig. 32. Gloeocapsa atrata, Fig. 33. Gloeocapsa kuetzingigiana, Fig. 34. Gloeocapsa livida, Fig. 35. Gloeocapsa muralis, Fig. 36. Gloeocapsa punctata, Figs 37-38: Gloeocapsa rupestris (Fig. 37. colony, Fig. 38. colonies showing cell division), Fig. 39. Gloeocapsa sanguinea, Fig. 40. Gloeothece rhodochlamys, Fig. 41. Gloeothece rupestris, Fig. 42. Aphanothece pallida, Fig. 43. Aphanothece stagnina, Fig. 44. Cyanothece aeruginosa, Fig. 45. Chroococcidiopsis kashayi, Fig. 46. Chroococcopsis fluviatilis. Scale bar: Figs $24-46=10 \mu \mathrm{m}$. 
Barberousse et al., 2006, p. 94, fig. 27.

Cells sub-spherical, olive green, arranged in more or less cubic and dense aggregates up to $20 \mu \mathrm{m}$ in diameter; cells 2-4 $\mu \mathrm{m}$ diameter.

Occurred as blackish crust on cement surface, Sarat, Mayurbhanj, Orissa; Voucher no.1263; Date of collection: 24/04/2007.

Reported from building facades, France (Barberousse et al. 2006). 30)

26. Cyanosarcina spectabilis (Geitler) Kováck (Pl. 2, Fig.

[Synonym: Myxosarcina spectabilis Geitler 1933]

Desikachary, 1959, p. 178, pl. 30, figs 1 \& 5.

Colony rounded, sometimes oval, divide in three planes, deep blue green to yellow green, colony $10-20 \mu \mathrm{m}$ in diameter; densely packed, containing variously pressed cells, 6.7-10.0 $\mu \mathrm{m}$ in diameter; sheath thin.

Occurred as blackish crust on brick surface, Sarat, Mayurbhanj, Orissa; Voucher no.1264; Date of collection: $25 / 04 / 2007$.

\section{Genus: Gloeocapsopsis Geitler ex Komárek}

27. Gloeocapsopsis crepidinum (Thuret) Geitler ex Komárek (Pl. 2, Fig. 31)

[Synonym: Gloeocapsa crepidium (Thuret) Thuret 1876]

(Basionym: Protococcus crepidium Thuret)

Desikachary, 1959, p. 117, pl. 27, fig. 4.

Thallus gelatinous, olive - green (when dried blackish), gelatinous, soft; colonies spherical, 12-24 $\mu \mathrm{m}$ diameter, closely arranged in the peripheral region and loosely arranged in the middle; cell in group of 2-4, rarely more, 4-8 $\mu \mathrm{m}$ diameter, sheath thin; yellowish - brown or colourless.

Occurred as greenish crust on limestone, Bhaskareswar temple, Bhubaneswar, Orissa; Voucher no. 1290; Date of collection: 13/07/2007.

\section{Genus: Chroococcidiopsis Geitler}

28. Chroococcidiopsis kashayi Friedmann (Pl. 2, Fig. 45)

Uher et al., 2005, p. 283, figs 5a-f.

Colonies blue or olive green, $10-20 \mu \mathrm{m}$ diameter; cell

2.5-7 $\mu \mathrm{m}$ diameter; granules present in the cell.

Occurred as greenish crust on lime coating surfaces of building wall, Athagarh, Ganjam, Orissa; Voucher no. 1305; Date of collection: 14/10/2007.

Reported from monument and building, South Eastern, Spain (Uher et al. 2005).

\section{Genus: Chroococcopsis Geitler}

29. Chroococcopsis fluviatilis (Lagerheim) Komárek and Anagnostidis (Pl. 2, Fig. 46)

[Synonym: Pleurocapsa fluviatilis Langerheim 1888]

Branco and Júnior, 1996, p. 39 \& 41, fig. 12.

Thallus hemispherical, firm, crusted, dark blue green, when older turning yellowish - orange; filaments short, radiating or parallel; sheath colourless; cell spherical or polygonal, 5.2-8.0 $\mu \mathrm{m}$ broad, 3.0-8.0 $\mu \mathrm{m}$ long, mostly broader than long.

Occurred as greenish crust on lime coated surface on wall of temple, Athagarh, Ganjam, Orissa; Voucher no.1305; Date of collection: 14/10/2007.

Family: Microcystaceae

\section{Genus: Gloeocapsa Kützing}

30. Gloeocapsa atrata Kützing (Pl. 2, Fig. 32)

[Synonym: Gloeocapsa montana Kützing 1843; Anacystis montana (Lightfoot) Drouet and Daily 1952] Desikachary, 1959 , p. 116, pl. 24, fig. 8 .

Thallus mucilaginous; cell 3.5-4.5 $\mu \mathrm{m}$ diameter, with sheath 9-15 $\mu \mathrm{m}$ diameter, pale blue-green, sheath colorless, indistinctly lamellate.

Occurred as greenish crust on cement surface of building wall; Utkal University campus, Bhubaneswar, Orissa; Voucher no. 1261; Date of collection: 02/03/2007.

31. Gloeocapsa kuetzingigiana Nägeli (Pl. 2, Fig. 33)

Desikachary, 1959, p. 119, pl. 23, fig. 4.

Cells densely aggregated in colonies up to $150 \mu \mathrm{m}$ diameter, cells without sheath 3-4 $\mu \mathrm{m}$ diameter, bluegreen, sheath yellow to brown, lamellated.

Occurred as blackish crust on rock surface, Khandagiri cave, Bhubaneswar, Orissa; Voucher no. 1278; Date of collection: 17/04/2007.

Reported from building facades, France (Barberousse et al., 2006); wall building and temples, Varanasi, India (Tripathi 1984).

32. Gloeocapsa livida (Carmichael) Kützing (Pl. 2, Fig. 34)

Desikachary, 1959, p. 116, pl. 27, fig. 8.

Cells spherical, small, bluish - green to olive in color, 3-4 $\mu \mathrm{m}$ diameter, with sheath 6-7 $\mu \mathrm{m}$ diameter.

Occurred as greenish crust on cement surface of building wall; Utkal University campus, Bhubaneswar, Orissa; Voucher no. 126; Date of collection: 02/03/2007.

33. Gloeocapsa muralis Kützing (Pl. 2, Fig. 35)

Tilden, 1910, p. 19, pl. I, fig. 23. 
Cells usually 4-6 together, blue green, 6-8 $\mu \mathrm{m}$ diameter, cell contents somewhat granulose; sheath spherical or elliptical, haline, colourless or yellowish.

Occurred as greenish crust on cement surface of building wall; Utkal University campus, Bhubaneswar, Orissa; Voucher no. 1261; Date of collection: 02/03/2007.

34. Gloeocapsa punctata Nägeli (Pl. 2, Fig. 36)

Desikachary, 1959, p. 115, pl. 23, fig. 2.

Thallus gelatinous, light blue green; cells 0.7-2.5 $\mu \mathrm{m}$ diameter, with sheath 3.5-6.5 $\mu \mathrm{m}$ broad, bluish green; sheath colorless, scarcely lamellated; cells 2-16 in group forming colonies.

Occurred as blackish crust on wall of Mukteswar temple, Bhubaneswar, Orissa; Voucher no. 1274; Date of collection: 17/04/2007.

\section{Gloeocapsa rupestris Kützing (Pl. 2, Figs 37-38)}

Tilden, 1910, p. 19, pl. 1, fig. 24.

Cells single or 2-4 together, spherical, in few celled colonies, blue-green; cells without sheath 6-8 $\mu \mathrm{m}$ in diameter and with sheath $12-15 \mu \mathrm{m}$ diameter; very distinctly lamellated; colonies 40-47 $\mu \mathrm{m}$ diameter.

Occurred as blackish crust on cement tiles at Baripada, Mayurbhanj, Orissa; Voucher no. 1326; Date of collection: 26/05/2007.

Reported from wall surface, Varanasi, India (Tripathi 1984); rock surface, Great Smoky Mountain, USA (Gomez et al. 2003).

36. Gloeocapsa sanguinea (Agardh) Kützing (Pl. 2, Fig. 39)

[Synonym: Haematococcus sanguineus C. Agardh; Gloeocapsa etzigsohnii Bornet 1882]

(Basionym: Haematococcus sanguineus C. Agardh)

Barberousse et al., 2006, p. 94, fig. 33, 72.

Cells spherical to oval, surrounded by distinctly stratified envelopes and distributed in intensely red, spherical mucilaginous colonies; 3-6 $\mu$ m diameter.

Occurred as blackish crust on cement wall surface, Sarat, Mayurbhanj, Orissa; Voucher no. 1263; Date of collection: 24/04/2007.

Reported from building facades, France (Barberousse et al. 2006).

Family: Cyanobacteriaceae

Genus: Gloeothece Nägeli

37. Gloeothece rhodochlamys Skuja (Pl. 2, Fig. 40)

Desikachary, 1959, p. 125, pl. 25, figs 13-14.
Colonies more or less rounded to spherical, blue green to reddish brown, 7.5-25.0 $\mu \mathrm{m}$ diameter; cells rounded to cylindrical, 2.5-3.7 $\mu \mathrm{m}$ broad, 2.5-7.5 $\mu \mathrm{m}$ long; sheath prominent, colourless or reddish brown, ensheathed cells 5.0-7.5 $\mu \mathrm{m}$ broad, $5-10 \mu \mathrm{m}$ long.

Occurred as blackish crust on brick surface, Sarat, Mayurbhanj, Orissa; Voucher no. 1264; Date of collection: $25 / 04 / 2007$.

38. Gloeothece rupestris (Lyngbye) Bornet (Pl. 2, Fig. 41) [Synonym: Palmella rupestris Lyngbye 1819; Gloeothece ruspestris var. maxima (W. West) Hollerbach 1938]

(Basionym: Palmella rupestris Lyngbye)

Desikachary, 1959, p. 127, pl. 25, fig. 4.

Cells ellipsoidal to long cylindrical, 4.4-5.5 $\mu \mathrm{m}$ broad and 8.8-9.9 $\mu \mathrm{m}$ long, with envelope 9.0-13.2 $\mu \mathrm{m}$ broad and 14.3-18.0 $\mu \mathrm{m}$ long, blue-green; usually $2-4$, sometimes 8 together in oval or sub -globose colony; colonies 22-24 $\mu \mathrm{m}$ broad and 35-41 $\mu \mathrm{m}$ long; envelope hyaline, distinctly lamellated.

Occurred on pinkish paint surface of building wall, Utkal University, Bhubaneswar, Orissa; Voucher no. 1279; Date of collection: 25/05/2007.

Reported from bed rock surface, Great Smoky Mountain, USA (Gomez et al. 2003).

\section{Genus: Aphanothece Nägeli}

39. Aphanothece pallida (Kützing) Rabenhorst (Pl. 2, Fig. 42)

[Synonym: Palmella pallida Kützing 1845]

(Basionym: Palmella pallida Kützing)

Desikachary, 1959, p. 140, pl. 22, fig. 3.

Thallus gelatinous, soft, some what transparent, pale blue green; cell 5.5-7.0 $\mu \mathrm{m}$ diameter, oblong-elliptical, usually scattered; cell content pale blue green.

Occurred as greenish crust on cement walls, Jorhat, Assam; Voucher no. 1269; Date of collection: 24/02/ 2007.

Reported from wetted wall, Lal Palma (Hrouzek and Šoun, 2004).

40. Aphanothece stagnina (Sprengel) A. Brown (Pl. 2, Fig. 43)

[Synonym: Coccochloris stagnina Sprengel 1807; Aphanothece prasina A. Braun 1863; Aphanothece piscinalis Rabenhorst 1865; Aphanothece mooreana (Harvey) Lagerheim 1883; Aphanothece tuberculata (Areschoug) Forti 1907]

Desikachary, 1959, p. 137, pl. 21, fig. 10. 
Thallus gelatinous, spherical or ellipsoidal; cell oblong or cylindrical, 4.0-5.5 $\mu \mathrm{m}$ broad, 6-8 $\mu \mathrm{m}$ long, dirty blue green, sparsely or densely arranged in the colony, without individual envelope, mucilage homogeneous.

Occurred on yellowish paint surface of building wall; Utkal University campus, Bhubaneswar, Orissa; Voucher no. 1280; Date of collection: 25/05/2 007.

\section{Genus: Cyanothece Komárek}

41. Cyanothece aeruginosa (Nägeli) Komárek (Pl. 2. Fig. 44)

[Synonym: Synechococcus aeruginosus Nägeli 1849]

Desikachary, 1959, p. 143, pl. 25, fig. 6.

Cells cylindrical, $6-16 \mu \mathrm{m}$ broad, up to $25 \mu \mathrm{m}$ long, single or 2-4 together, pale blue green.

Occurred as brownish crust on wall, Utkal University campus, Bhubaneswar, Orissa; Voucher no. 1309.

Date of collection: 12/10/2007.

Order: Oscillatoriales

Family: Phormidiaceae

\section{Genus: Phormidium Kützing ex Gomont}

42. Phormidium aerugineo-coeruleum (Gomont) Anagnostidis and Komárek (Pl. 3, Fig. 47)

[Synonym: Lyngbya aerugineo-coerulea Gomont 1892]

Desikachary, 1959, p. 315, pl. 48, fig. 9.

Filament flexuous, single or forming dark blue green aggregates; sheath thin; trichomes pale blue green, 3.6$6.8 \mu \mathrm{m}$ broad, not constricted at the cross walls; cells quadrate, $1 \frac{1}{2}$ long as broad, 2.3-4.0 $\mu \mathrm{m}$ long, pale blue green; end cell rounded.

Occurred as brownish crust on the limestone of Bhaskareswar temple, Bhubaneswar, Orissa; Voucher no. 1290; Date of collection: 13/07/2007.

Reported from bed rock surface, Great Smoky Mountain, USA (Gomez et al., 2003).

43. Phormidium autumnale (Agardh) Gomont (Pl. 3, Fig. 48)

[Synonym: Phormidium autumnale (C. Agardh) Gomont 1892]

(Basionym: Oscillatoria autumnalis C. Agardh)

Desikachary, 1959, p. 276, pl. 44, fig. 24.

Thallus expanded, dark blue green or brownish green, sometimes yellowish; filament straight, rarely flexuous, variously entangled; sheath firm; trichomes not constricted at the cross wall, 4.8-5.0 $\mu \mathrm{m}$ broad, ends attenuated, straight or scarcely curved, prominently capitate; cell 5-6 $\mu \mathrm{m}$ long; end cell with a rounded or truncated conical calyptra.

Occurred as blackish green on cement surface of building wall, Baramunda, Bhubaneswar, Orissa; Voucher no. 1308; Date of collection: 02/06/2007.

Reported from building wall, Nosa Señora da Esclavitude, Galicia, Spain (Noguerol-Seoane and RifónLastra, 2003); wetted wall Lal Palma (Hrouzek and Šoun, 2004); brick and whitewashing surface of cultural monuments, Ukraine (Darienko and Hoffmann, 2003); Urban wall, Europe (Rindi and Guiry, 2004); moist wall, Varanasi, India (Tripathi, 1984); building stone, Salamanca and Toledo, Spain (Ortega-Calvo, 1993).

44. Phormidium retzii (Agardh) Gomont (Pl. 3, Fig. 49)

[Synonym: Oscillatoria retzii C. Agardh 1812; Conferra retzii (C. Agardh) Sommerfelt 1826; Phormidium retzii (C. Agardh) Kützing 1843; Microcoleus retzii (C. Agardh) Rabenhorst 1847; Lyngbya retzii (C. Agardh) Hansgirg 1892]

(Basionym: Oscillatoria retzii C. Agardh)

Desikachary, 1959, p. 268, pl. 44, fig. 15.

Thallus blue green; filament straight, not constricted at the cross walls, not attenuated at the ends; cells 4.0 -5.5 $\mu \mathrm{m}$ long and 6-9 $\mu \mathrm{m}$ broad.

Occurred as greenish mat on cement surface of building wall, Utkal University, Bhubaneswar, Orissa; Voucher no. 1308; Date of collection: 02/06/2007.

Genus: Pseudophormidium (Forti) Anagnostidis and Komárek

45. Pseudophormidium indicum (Dixit) Anagnostidis and Komárek (Pl. 3, Fig. 50)

[Synonym: Plectonema indica Dixit]

Desikachary, 1959, p. 435, pl. 83, fig. 2.

Thallus expanded; filament irregularly curved; bluegreen; sheath firm; trichome 6.6-7.5 $\mu \mathrm{m}$ broad; cell quadratic or cylindrical, slightly constricted at the joints; end cells rounded.

Occurred as brownish crust on limestone quarry, Shillong, Meghalaya; Voucher no.1249; Date of collection: $10 / 12 / 2007$.

46. Pseudophormidium radiosum (Gomont) Anagnostidis and Komárek 1892 (Pl. 3, Fig. 51)

[Synonym: Plectonema radiosum Gomont]

Desikachary, 1959, p. 437, pl. 83, fig. 8.

Filaments irregularly curved, rounded or spherical, about $\frac{1}{2}$ long, dull green; richly false branching, sheath in lower part of the filament; cells distinctly constricted 

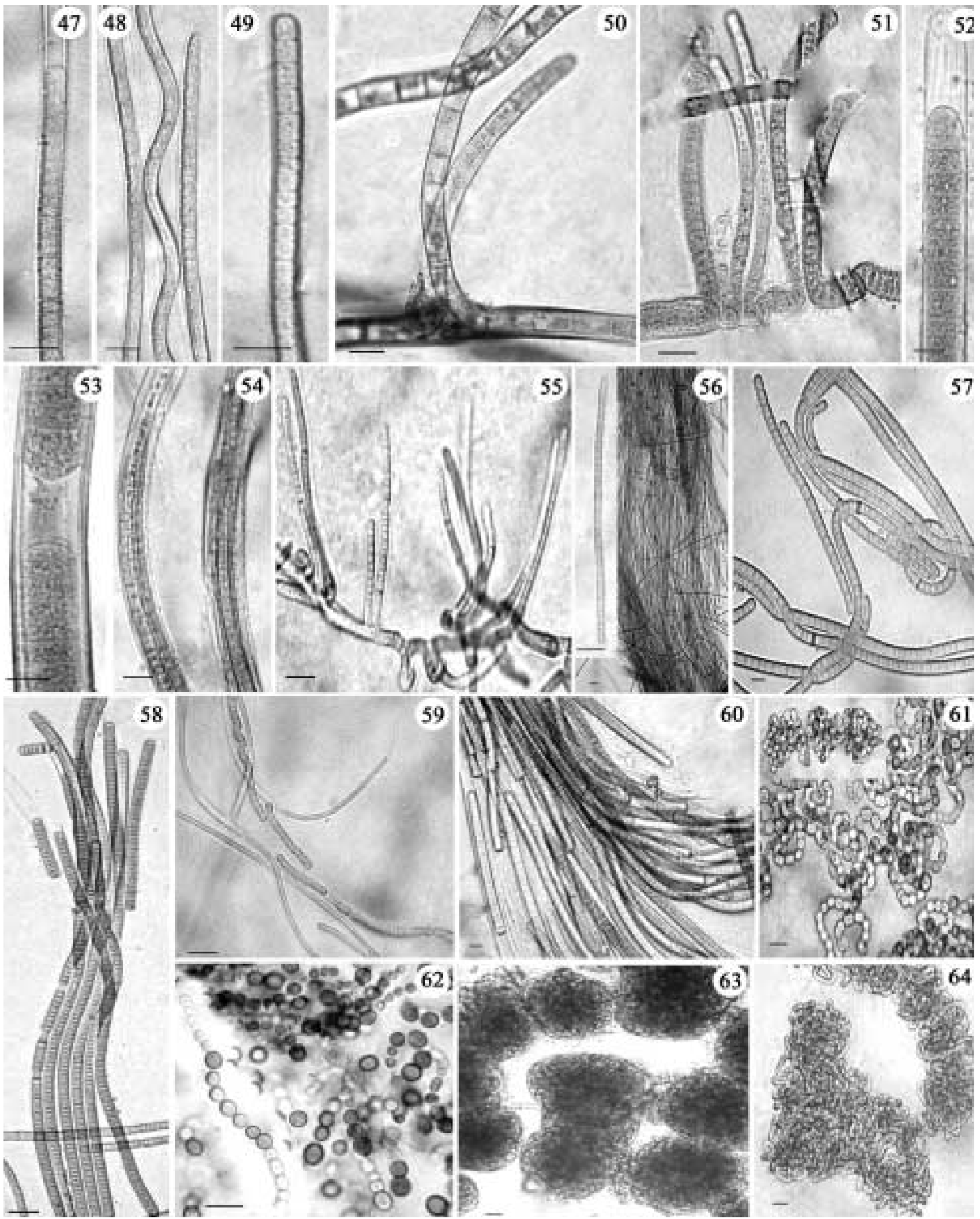

Plate 3. Fig. 47. Phormidium aerugineo - coeruleum, Fig. 48. Phormidium autumnale, Fig. 49. Phormidium retzii, Fig. 50. Pseudophormidium indicum, Fig. 51. Pseudophormidium radiosum, Figs 52-53. Porphyrosiphon ceylanicus, Fig. 54. Microcoleus paludosus, Fig. 55. Leptolyngbya boryana, Fig. 56. Leptolyngbya fragilis, Fig. 57. Leptolyngbya nostocorum, Fig. 58. Leptolyngbya polysiphoniae, Fig. 59. Leptolyngbya notata, Fig. 60. Schizothrix lateritia, Fig. 61. Nostoc commune, Fig. 62. Nostoc linckia, Fig. 63. Nostoc microscopicum, Fig. 64. Nostoc punctiforme. Scale bar: Figs $47-64=10 \mu \mathrm{m}$. 
at the cross walls, 11-20 $\mu \mathrm{m}$ broad, 3-10 $\mu \mathrm{m}$ long, blue green, end cell rounded.

Occurred as dark greenish crust on cement walls, Barg, Zorhat, Assam: Voucher no. 1268; Date of collection: $24 / 02 / 2007$.

\section{Genus: Porphyrosiphon Kützing ex Gomont}

47. Porphyrosiphon ceylanicus (Wille) Anagnostidis \& Komárek (Pl. 3, Figs 52-53)

[Synonym: Lyngbya ceylanica Wille 1914]

Desikachary, 1959, p. 299, pl. 54, fig. 4.

Thallus extensive, dark blue green; filament with sheath $13-14 \mu \mathrm{m}$ broad; sheath thin, colorless, when old often red, trichome blue green, not constricted at the joints, not attenuated at the end; cell quadrate, 13-16 $\mu \mathrm{m}$ broad, 7-10 $\mu \mathrm{m}$ long; end cell round.

Occurred as blackish crust on rock surface of Khandagiri cave, Bhubaneswar, Orissa; Voucher no. 1265;

Date of collection: 17/04/2007.

\section{Genus: Microcoleus Desmazières ex Gomont}

48. Microcoleus paludosus (Kützing) Gomont (Pl. 3, Fig. 54)

[Synonym: Chthonoblastus paludosus Kützing]

Desikachary, 1959, p. 344, pl. 56, fig. 2.

Filament single or composed of transparent sheath containing 4-7 trichomes, cells in the trichome not constricted at joints, parallel, straight or twisted, cell 4-6 $\mu \mathrm{m}$ broad and 5-7 $\mu \mathrm{m}$ long; blue green, apical cell not capitate.

Occurred as brownish crust on wall, Utkal University campus, Bhubaneswar, Orissa; Voucher no.1325; Date of collection: 15/10/2007.

Family: Schizotrichaceae

\section{Genus: Schizothrix Kützing ex Gomont}

49. Schizothrix lateritia (Kützing) Gomont (Pl. 3, Fig. 60)

[Synonym: Hypheothrix lateritia Kützing 1849; Lyngbya lateritia (Kützing) Kirchner 1878; Lyngbya lateritia (Kützing) Kirchner ex Hansgirg 1892]

(Basionym: Hypheothrix lateritia Kützing)

Desikachary, 1959, p. 330, pl. 57, figs 9-10.

Thallus brownish green, filament arranged in creeping bundle; sheath golden yellow or gelatinous; trichome slightly constricted at the cross walls; cells $7-9 \mu \mathrm{m}$ broad, $4-5 \mu \mathrm{m}$ long; end cells obtuse.

Occurred as brownish crust on the lime washed wall, temple boundary, Rasulgarh, Bhubaneswar, Orissa;
Voucher no. 1310; Date of collection: 19/07/2007.

Family: Oscillatoriaceae

Genus: Plectonema Thuret ex Gomont

50. Plectonema puteale (Kirchner) Hansgirg (Pl. 4, Fig. 65)

[Synonym: Glaucothrix putealis Kirchner]

Desikachary, 1959, p. 439.

Filament pale blue or yellow - green; false branches mostly short; slightly constricted at the cross wall; sheath thin; cells $3.0-4.5 \mu \mathrm{m}$ broad.

Occurred as brownish crust on wall, Utkal University campus, Bhubaneswar, Orissa; Voucher no.1323;

Date of collection: 12/10/2007.

Order: Pseudanabaenales

Family: Pseudanabaenaceae

Genus: Leptolygnybya Anagnostidis and Komárek

51. Leptolyngbya boryana (Gomont) Anagnostidis and Komárek (Pl. 3, Fig. 55)

[Synonym: Plectonema boryanum Gomont 1899]

Ortega-Calvo et al. 1993, p. 244, fig. 9.

Thallus pale green; trichome variously curved or straight, constriction at the cross - walls, especially in younger zones; cells 3-4 $\mu \mathrm{m}$ broad, shorter than broad, quadrate.

Occurred as brownish crust on the wall, Bhaskareswar temple, Bhubaneswar, Orissa: Voucher no. 1289; Date of collection: 13/07/2007.

Reported from building stone, Salamanca and Toledo, Spain (Ortega-Calvo et al. 1993).

52. Leptolyngbya fragilis (Gomont) Anagnostidis and Komárek (Pl. 3, Fig. 56)

[Synonym: Phormidium fragile Gomont 1892]

Desikachary, 1959, p. 253, pl. 44, fig. 2.

Thallus mucilaginous, dark blue green; sheath gelatinous, fibrous, diffluent into mucus; trichome 1-2 $\mu \mathrm{m}$ diameter, more or less flexous, entangled or some what parallel to each other, constricted at the joints; apical cell acute conical; cells 1.2-2.3 $\mu \mathrm{m}$ broad, 1.2-3.0 $\mu \mathrm{m}$ long.

Occurred as greenish mat on rock surface of Khandagiri cave entrance, Bhubaneswar, Orissa; Voucher no. 1292; Date of collection: 13/07/2007.

Reported from building stone, Salamanca and Toledo, Spain (Ortega-Calvo et al. 1993).

53. Leptolyngbya nostocorum (Borent ex Gomont) Anagnostidis and Komárek (Pl. 3, Fig. 57) 


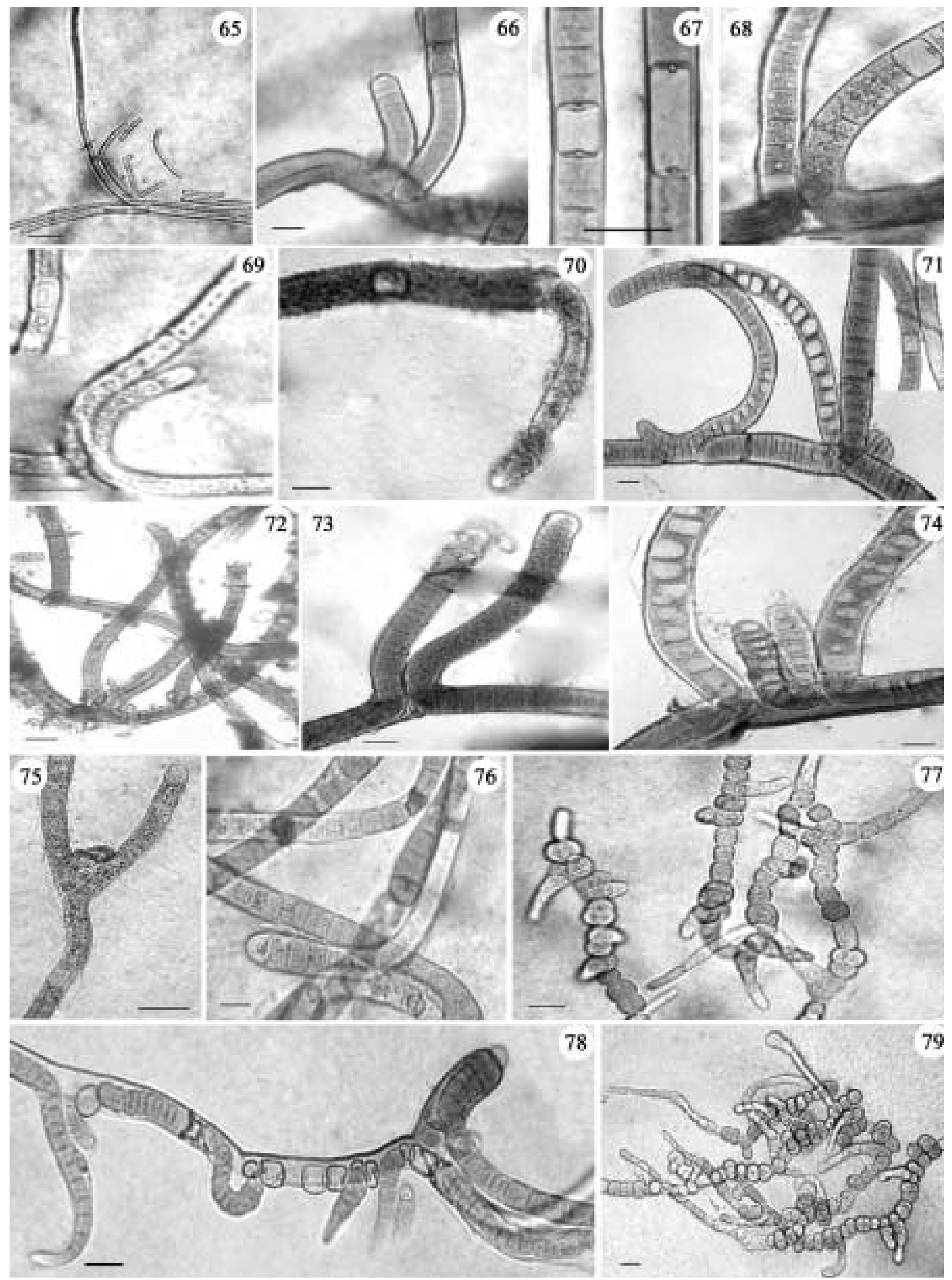

Plate 4. Fig. 65. Plectonema puteale, Figs 66-67. Scytonema bohneri, Fig. 66. Filament with false branch, Fig. 67. Showing heterocyst, ellipsoidal to cylindrical, Fig. 68. Scytonema crispum, Fig. 69. Scytonema geitleri, Fig. 70. Scytonema hofman-bangii, Fig. 71. Scytonema millei, Fig. 72. Scytonema multiramosum, Fig. 73. Scytonema ocellatum, Fig. 74. Scytonema pseudoguyanense, Fig. 75. Tolypothrix fragilis, Fig. 76. Calothrix fusca, Fig. 77. Westiellopsis prolifica, Fig. 78. Calothrix wembaerensis, Fig. 79. Stigonema tomentosum. Scale bar: Figs 65-79 = $10 \mu \mathrm{m}$. 
[Synonym: Plectonema nostocorum Bornet ex Gomont 1892]

(Basionym: Plectonema nostocorum Bornet ex Gomont)

Uher et al., 2005, p. 285, fig. 11.

Thallus dark green; filament with necridic cells, hormogonia flexuous, with a very thin sheath; cells isodiametric or wider than long, 3-5 $\mu \mathrm{m}$ diameter, slightly constricted at the cross wall; apical cells widely conical, with round apex.

Occurred as greenish crust on the rock surface, Bhaskareswar temple, Bhubaneswar, Orissa; Voucher no.1288; Date of collection: 13/07/2007.

54. Leptolyngbya notata (Schmidle) Anagnostidis and Komárek (Pl. 3, Fig. 59)

[Synonym: Plectonema notatum Schmidle 1901]

Desikachary, 1959, p. 440, pl. 83, fig. 5.

Filament yellowish - green, short branched; sheath firm, thin, colourless; cells disc - shaped, 2.5-4.0 $\mu \mathrm{m}$ broad.

Occurred as brownish crust on the lime washed wall, temple boundary, Rasulgarh, Bhubaneswar, Orissa; Voucher no. 1310; Date of collection: 19/07/2007.

55. Leptolyngbya polysiphoniae (Frémy) Anagnostidis (P1. 3, Fig. 58)

[Synonym: Lyngbya polysiphoniae Frémy]

Desikachary, 1959, p. 287, pl. 53, figs 4-5.

Filament straight or curved, single or in bundle; sheath very thin, delicate, papyraceous, colourless; trichome pale blue-green; constricted at the cross walls, about 2 $\mu \mathrm{m}$ broad, apics not attenuated; cell as long as broad; end cells ronded.

Occurred as brownish crust on limestone quarry, Shillong, Meghalaya; Voucher no.1249; Date of collection: 10/12/2007.

Order: Nostocales

Family: Nostocaceae

Genus: Nostoc Vaucher ex Bornet and Flahault

56. Nostoc commune Vaucher ex Bornet \& Flahault (Pl.

3. Fig. 61)

[Synonym: Nostocella communis (Vaucher) Gaillon; Tremella nostoc Linnaeus 1753; Nostoc commune Vaucher 1803; Nostoc kurzianum Zeller 1873]

Desikachary, 1959, p. 378, pl. 68, fig. 3.

Thallus blue green, olive or brown in colour; filament flexous, entangled; distinct thick sheath; cell small, depressed, spherical or barrel-shaped, 4-6 $\mu \mathrm{m}$ diameter; heterocyst intercalary, sub-spherical, $4-5 \mu \mathrm{m}$ diameter.

Occurred as brownish patches on building roof surface, Village - Maniakati, Ganjam, Orissa: Voucher no. 1304; Date of collection: 14/10/2007.

Reported from building facades, France (Barberousse et al., 2006); bedrock surface, Great Smoky Mountain, USA (Gomez et al., 2003).

57. Nostoc linckia (Roth) Bornet ex Bornet \& Flahault (Pl. 3, Fig. 62)

[Synonym: Nostoc linckia (Roth) Bornet 1880; Stratonostoc linckia (Roth) Elenkin 1938]

Desikachary, 1959, p. 377, pl. 69, fig. 4.

Thallus small in size, punctiform, globose first later expanding, blue green in colour, becoming dirty green; trichome much entangled, twisted; cells barrel shaped, 3$4 \mu \mathrm{m}$ diameter; heterocyst sub- spherical to ovate, $4-6 \mu \mathrm{m}$ diameter.

Occurred on lime washed of building wall, Utkal University, Bhubaneswar, Orissa: Voucher no. 1303; Date of collection: 25/05/2007.

Reported from limestone cultural monuments, Ukraine (Darienko and Hoffmann, 2003); bedrock surface, Great Smoky Mountain, USA (Gomez et al., 2003).

58. Nostoc microscopicum Carmichael ex Bornet and Flahault (Pl. 3. Fig. 63)

[Synonym: Nostoc microscopicum Carmichael 1833]

Barberousse et al., 2006. p. 96, fig. 46, 81-82.

Trichomes composed by short barrel-shaped cells, deeply constricted at the cross walls, densely entangled, surrounded by spherical, firm and yellow mucilage; heterocyst sub-spherical, terminal or intercalary; cells 4-5 $\mu$ m diameter.

Occurred as greenish crust on lime washed cement surface, Utkal University, Bhubaneswar, Orissa: Voucher no. 1298; Date of collection: 16/08/2007.

Reported from building wall, Nosa Señora da Esclavitude, Galicia, Spain (Noguerol - Seoane and Rifón - Lastra 2003); building façade, France (Barberousse et al. 2006); bed rock surface, Great Smoky Mountain, USA (Gomez et al. 2003).

59. Nostoc punctiforme (Kützing) Hariot (Pl. 3, Fig. 64)

[Synonym: Nostoc hederulae Meneghini 1849]

Desikachary, 1959, p. 374, pl. 69, fig. 1.

Colonies spherical, olive or dark blue green, finally becoming brownish; filament short, united to form a globose mass, coiled, densely entangled; sheath distinct, 
colourless or rarely yellowish; cell small, spherical to sub-spherical, $4 \mu \mathrm{m}$ diameter.

Occurred on brownish patch on building roof surface, Village - Maniakati, Ganjam, Orissa: Voucher no. 1304; Date of collection: 14/10/2007.

Reported from building wall, Nosa Señora da Esclavitude, Galicia, Spain (Noguerol-Seoane and Rifón -Lastra, 2003); whitewashing surfaces of cultural monument, Ukraine (Darienko and Hoffmann 2003).

Family: Scytonemataceae

\section{Genus: Scytonema Agardh ex Bornet and Flahault}

60. Scytonema bohneri Schmidle (Pl. 4, Figs 66-67)

Desikachary, 1959, p. 457, pl. 87, fig. 1.

Thallus dark blue green; filament long, partly creeping, false branched, 10-13 $\mu \mathrm{m}$ broad, narrow at the apex, 6-7 $\mu \mathrm{m}$ broad; sheath colourless and thick; trichome blue green, not constricted at the cross walls; cell rectangular 5-8 $\mu \mathrm{m}$ broad; heterocyst intercalary, ellipsoidal to cylindrical, colourless or yellowish, 8-10 $\mu \mathrm{m}$ broad, 6-12 $\mu \mathrm{m}$ long.

Occurred as brownish crust on painted wall of building, Rajmahal square, Unit-III, Bhubaneswar, Orissa; Voucher no. 1306; Date of collection: 12/10/2007.

61. Scytonema crispum (Agardh) Bornet (Pl. 4, Fig. 68)

[Synonym: Scytonema cincinnatum Thuret ex Bornet and Flahault]

(Basionym: Lyngbya cincinnata Kützing)

Desikachary, 1959, p. 453, pl. 93, fig. 1.

Thallus brownish green, olivaceous; filaments long, variously bent or curved, false branched; sheath firm, hyaline, brownish; trichome $14-20 \mu \mathrm{m}$ broad, $13-14 \mu \mathrm{m}$ long.

Occurred as greenish crust on Maplong Dam, Shillong, Meghalaya; Voucher no. 1248; Date of collection: 10/12/2007.

62. Scytomema geitleri Bharadwaja (Pl. 4, Fig. 69)

Desikachary, 1959, p. 481, pl. 94, fig. 5.

Thallus brownish or dark green; filament irregularly curved; sheath firm; trichome $4.0-5.5 \mu \mathrm{m}$ broad, slightly constricted at the joints; cell cylindrical, sometimes rounded or barrel-shaped at the short branches; heterocyst cylindrical or rectangular, 5-7 $\mu \mathrm{m}$ broad, 6-7 $\mu \mathrm{m}$ long.

Occurred as blackish crust on building wall, Utkal University campus, Bhubaneswar, Orissa; Voucher no. 1298; Date of collection: 16/08/2007.
Reported from wall and roof top, Varanasi, India (Tripathi, 1984).

63. Scytonema hofman- bangii Agardh ex Silva (Pl. 4, Fig. 70)

[Synonym: Scytonema hofmanni C. Agardh ex Bornet and Flahault 1887]

Desikachary, 1959, p. 476, pl. 91, fig. 2.

Thallus olive to blue green; filament long, false branched, aggregated in vertical fascicles; cells unequal in length, 7.7-14.3 $\mu \mathrm{m}$ broad, 4.0-5.5 $\mu \mathrm{m}$ long,; heterocyst oblong.

Occurred as brownish crust on rock surface, Temple, Koraput, Oirssa; Voucher no. 1285; Date of collection: 19/05/2007.

Reported from wetted wall, Lal Palma (Hrouzek and Šoun, 2004).

64. Scytomema millei Bornet ex Bornet and Flahault (Pl. 4, Fig. 71)

Desikachary, 1959, p. 460, pl. 93, figs 2-3.

Thallus expanded, brownish; filament long, false branched; sheath firm, yellowish -brown; cell 10-15 $\mu \mathrm{m}$ broad, compressed; heterocyst nearly quadratic or longer than broad, $8.0-9.5 \mu \mathrm{m}$ broad, $8 \mu \mathrm{m}$ long.

Occurred as blackish crust on moist building wall, Utkal University campus, Bhubaneswar, Orissa; Voucher no. 1303; Date of collection: 19/08/2007.

65. Scytomema multiramosum Gardner (Pl. 4, Fig. 72)

Desikachary, 1959, p. 475, pl. 92, fig. 4.

Thallus blue-green; filaments long, $10-14 \mu \mathrm{m}$ broad, 1.5-2.5 $\mu \mathrm{m}$ long, false branching, sheath thick, slightly gelatinous; cell at the apex slightly barrel shaped; heterocyst oblong, yellowish, $14 \mu \mathrm{m}$ broad.

Occurred as blackish crust on rock surface, Hatigumpha cave, Khandagiri, Bhubaneswar, Orissa; Voucher no. 1262; Date of collection: 20/03/2007.

66. Scytonema ocellatum (Lyngbye) Bornet and Flahault (Pl. 4, Fig. 73)

[Synonym: Scytonema cinereum Meneghini 1837; Scytonema murale Zeller 1873]

Desikachary, 1959, p. 467, pl. 92, fig. 3.

Thallus expanded, grayish blue; filaments 10.0-16.5 $\mu \mathrm{m}$ broad, erect, false branched, less constricted at the cross walls; sheath firm; trichome $6-14 \mu \mathrm{m}$ broad; apical cell rounded; heterocyst sub-quadrate or cylindrical to discoid, yellowish, $12.0-13.2 \mu \mathrm{m}$ broad, $9.9-12.0 \mu \mathrm{m}$ long. 
Occurred as brownish crust on the wall, Bhaskareswar temple, Bhubaneswar, Orissa; Voucher no. 1289; Date of collection: 17/04/2007.

67. Scytonema pseudoguyanense Bharadwaja (Pl. 4, Fig. 74)

Desikachary, 1959, p. 472, pl. 89, fig. 2.

Thallus erect, brownish green; filaments irregularly curved and densely entangled, $16 \mu \mathrm{m}$ broad, false branching numerous, narrower than the main filament; heterocyst yellowish, prominent, quadratic, $13 \mu \mathrm{m}$ broad, 7-13 $\mu \mathrm{m}$ long.

Occurred as dark greenish crust on wall, Parasurameswar temple, Bhubaneswar, Orissa; Voucher no. 1273; Date of collection: 17/04/2007.

Family: Microchaetaceae

\section{Genus: Tolypothrix Gardner}

68. Tolypothrix fragilis (Gardner) Geitler (Pl. 4, Fig. 75)

[Synonym: Hassallia fragilis Gardner 1927]

Desikachary, 1959, p. 500, pl. 103, fig. 1.

Thallus dark blue green; filament straight, forming a thin thallus; sheath thin, colourless; trichome not constricted at the cross wall; cell 5-7 $\mu \mathrm{m}$ broad; heterocyst spherical or ellipsoidal.

Occurred as blackish crust on building wall, Utkal University campus, Bhubaneswar, Orissa; Voucher no. 1299; Date of collection: 16/08/2007.

Reported from building terraces and walls, Varanasi, India (Tripathi 1984).

\section{Family: Rivulariaceae}

\section{Genus: Calothrix Agardh ex Bornet and Flahault}

69. Calothrix fusca (Kützing) Bornet and Flahault (Pl. 4, Fig. 76)

Desikachary, 1959, p. 527, pl. 107, fig. 10.

Thallus gelatinous; filament single, unbranched, straight or slightly bent, 11-12 $\mu \mathrm{m}$ broad; sheath broad, colourless; cell often discoid, shorter than broad; heterocyst basal or hemispherical, yellowish.

Occurred as blackish crust on roof floor of building; Utkal University campus, Bhubaneswar, Orissa; Voucher no. 1318; Date of collection: 14/10/2007.

70. Calothrix wembaerensis Hieronimus and Schmidle (Pl. 4, Fig. 78)

Desikachary, 1959, p. 526, pl. 110, figs 1-7.

Filament branched, caespitose, $10-15 \mu \mathrm{m}$ broad; sheath thick, colourless, gelatinous; trichome $6-8 \mu \mathrm{m}$ broad; cells at the base of filament about $8-10 \mu \mathrm{m}$ broad, barrel shaped; heterocyst basal, mostly two; spores cylindrical with rounded ends, separated from each other by heterocyst.

Occurred as blackish crust on fort wall (on mortar paste), Nahargarh, Jaipur, Rajasthan; Voucher no. 1314; Date of collection: 25/10/2007.

Family: Hapalosiphonaceae

\section{Genus: Westiellopsis Janet}

71. Westiellopsis prolifica Janet (Pl. 4, Fig. 77)

Desikachary, 1959, p. 596, pl. 131, figs 1-12.

Thallus blue green; filament with prostrate and erect branches, lateral branch thinner than main branch, 6-7 $\mu \mathrm{m}$ broad, 9-12 $\mu \mathrm{m}$ long; cell spherical or elliptical 5-6 $\mu \mathrm{m}$ diameter; heterocyst intercalary, light yellow, rectangular, 4-6 $\mu \mathrm{m}$ broad, 8-10 $\mu \mathrm{m}$ long.

Occurred as greenish patch on lime washed building wall, Saheed nagar, Bhubaneswar, Orissa; Voucher no. 1302; Date of collection: 13/10/2007.

Family: Stigonemataceae

\section{Genus: Stigonema Agardh ex Bornet and Flahault}

72. Stigonema tomentosum (Kützing) Hieronymus (Pl. 4, Fig. 79)

[Synonym: Sirosiphon tomentosus Kützing 1847

(Basionym: Sirosiphon tomentosus Kützing)

Desikachary, 1959, p. 475, pl. 92, fig. 4.

Thallus greenish, spongy, branched, $20-28 \mu \mathrm{m}$ broad; trichome long, primary branch 2-3 celled only at few portion of the thallus; cell spherical, elongated, 4-5 $\mu \mathrm{m}$ broad, 5-9 $\mu \mathrm{m}$ long, secondary branch single celled; heterocyst on both primary and secondary branches, 6-10 $\mu \mathrm{m}$ broad, $10-14 \mu \mathrm{m}$ long.

Occurred as dark greenish crust on wetted rocky wall, Parasurameswar temple, Bhubaneswar, Orissa; Voucher no. 1287; Date of collection: 17/08/2007.

\section{DISCUSSION}

The micro-algae and cyanobacteria recorded from the exterior of several buildings and monuments in India during the hot summer months (March - June) and soon after monsoon rain (July - August) have been given in Table 2. Analysis of these results showed that only one species of Trentepholia, T. abietina var. tenue under chlorophyta and four species of cyanobacteria e.g. Chroococcidiopsis kashayi, Pseudophormidium indicum, Plectonema puteale and Scytonema geitleri occur on the 
Table 2. List of Cyanobacteria and micro-algae occurred as crust on exposed surfaces of building facades and rocky walls of monuments during summer and after monsoon rain

\begin{tabular}{|c|c|c|c|}
\hline Site & Organism & Summer & After rain \\
\hline & Chlorophyta & & \\
\hline 1. & Chlorococcum infusionum & + & - \\
\hline 2. & Bracteacoccus minor & - & + \\
\hline 3. & Radiococcus nimbatus & - & + \\
\hline 4. & Coenochloris pyrenoidosa & - & + \\
\hline 5. & Gloeocystis polydermatica & + & - \\
\hline 6. & Chlorella vulgaris & - & + \\
\hline 7. & Scenedesmus arcuatus & + & - \\
\hline 8. & Scenedesmus bijugatus & - & + \\
\hline 9. & Trentepohlia aurea & + & - \\
\hline 10. & Trentepohlia abietina var. tenue & + & + \\
\hline 11. & Trentepohlia rigidula & - & + \\
\hline 12. & Trentepohlia umbrina & - & + \\
\hline 13. & Printzina effusa & + & - \\
\hline 14. & Cosmarium misellum & - & + \\
\hline \multirow[t]{2}{*}{15.} & Cosmarium nitidulum & - & + \\
\hline & Cyanophyta (Cyanobacteria) & & \\
\hline 16. & Chroococcus indicus & + & - \\
\hline 17. & Chroococcus limneticus & + & - \\
\hline 18. & Chroococcus lithophilus & - & + \\
\hline 19. & Chroococcus minor & + & - \\
\hline 20. & Chroococcus pallidus & - & + \\
\hline 21. & Chroococcus schizodermaticus & + & - \\
\hline 22. & Chroococcus varius & + & - \\
\hline 23. & Asterocapsa divina & + & - \\
\hline 24. & Cyanosarcina burmensis & - & + \\
\hline 25. & Cyanosarcina parthenonensis & + & - \\
\hline 26. & Cyanosarcina spectabilis & + & - \\
\hline 27. & Gloeocapsopsis crepidium & - & + \\
\hline 28. & Chroococcidiopsis kashayi & + & + \\
\hline 29. & Chroococcopsis fluviatilis & - & + \\
\hline 30. & Gloecapsa atrata & + & - \\
\hline 31. & Gloeocapsa kuetzingigiana & + & - \\
\hline 32. & Gloeocapsa livida & + & - \\
\hline 33. & Gloeocapsa muralis & + & - \\
\hline 34. & Gloeocapsa punctata & + & - \\
\hline 35. & Gloeocapsa rupestris & + & - \\
\hline 36. & Gloeocapsa sanguinea & + & - \\
\hline 37. & Gloeothece rhodochlamys & + & - \\
\hline 38. & Gloeothece rupestris & + & - \\
\hline 39. & Aphanothece pallida & - & + \\
\hline 40. & Aphanothece stagnina & - & + \\
\hline 41. & Cyanothece aeruginosa & - & + \\
\hline 42. & Phormidium aerugineo-coerulum & - & + \\
\hline 43. & Phormidium autumnale & - & + \\
\hline 44. & Phormidium retzii & + & + \\
\hline 45. & Pseudophormidium indicum & - & + \\
\hline 46. & Pseudophormidium radiosum & - & + \\
\hline 47. & Porphyrosiphon ceylanicus & + & + \\
\hline 48. & Microcoleus paludosus & - & + \\
\hline 49. & Leptolyngbya boryana & - & + \\
\hline 50. & Leptolyngbya fragilis & - & + \\
\hline 51. & Leptolyngbya nostocorum & - & + \\
\hline
\end{tabular}


Table 2. (continued)

\begin{tabular}{|c|c|c|c|}
\hline Site & Organism & Summer & After rain \\
\hline 52. & Leptolyngbya notata & - & + \\
\hline 53. & Leptolyngbya polysiphoniae & - & + \\
\hline 54. & Schizothrix lateritia & - & + \\
\hline 55. & Nostoc commune & - & + \\
\hline 56. & Nostoc linckia & - & + \\
\hline 57. & Nostoc microscopicum & - & + \\
\hline 58. & Nostoc punctiforme & - & + \\
\hline 59. & Plectonema puteale & + & + \\
\hline 60. & Scytonema bohneri & - & + \\
\hline 61. & Scytonema crispum & - & + \\
\hline 62. & Scytomema geitleri & + & + \\
\hline 63. & Scytonema hofman-bangii & - & + \\
\hline 64. & Scytonema millei & - & + \\
\hline 65. & Scytomema multiramosum & + & - \\
\hline 66. & Scytonema ocellatum & + & + \\
\hline 67. & Scytonema pseudoguyanense & + & + \\
\hline 68. & Tolypothrix fragilis & - & + \\
\hline 69. & Calothrix fusca & - & + \\
\hline 70 & Calothrix wembaerensis & - & + \\
\hline 71. & Westiellopsis prolifica & - & + \\
\hline 72. & Stigonema tomentosum & - & + \\
\hline
\end{tabular}

exterior of building walls all through the year. On the contrary, on the exposed rock surface of temples and monuments, where the temperature can exceed $60^{\circ} \mathrm{C}$ during summer months, only three cyanobacteria species e.g. Porphyrosiphon ceylanicus, Scytonema ocellatum and S. pseudoguyanense occur. These species form a characteristic blackish-brown crust, and develop into a thick mat up to 3 to $4 \mathrm{~mm}$ thick upon receiving water during the rainy season.

In addition to the above species, five other green algal species (Chlorococcum infusionum, Scenedesmus arcuatus, Trentepholia aurea, Gloeocystis polydermatica and Printzina effuse) and 18 other cyanobacterial taxa in the genera Chroococcus (5), Asterocapsa (1), Cyanosarcina (2), Gloeocapsa (7), Gloeothece (2), and Scytonema (1) occur in the biofilms during summer months showing their ability to thrive under conditions of high desiccation and heat stress prevailing on the buildings facades and exterior of rocks of monuments (Table 2). However, with the onset of monsoon rains when these biofilms receive water along with a humid microenvironment, 10 green algal taxa belonging to eight genera, e.g. Chlorella (1), Brateacoccus (1), Radiococcus (1), Coenochloris (1), Gloeocystis (1), Scenedesmus (1), Trentepholia (2), cosmarium (2), and 29 cyanobacteria taxa in 17 genera, e.g. Chroococcus (2), Gloeocapsopsis (1), Aphanothece (2), Cyanothece (1), Cyanosarcina (1), Chroococcidiopsis (1),
Phormidium (2), Pseudophormidium (1), Microcoleus (1), Leptolyngbya (4), Schizothrix (1), Nostoc (4), Scytonema (4), Tolypothrix (1), Calothrix (1), Westiellopsis (1) and Stigonema (1) occurred and formed the characteristic flora on the sub-aerial habitats of different regions in India (Table 2). Of the total 72 algal taxa, 22 species have not been recorded from sub-aerial habitats of other countries in the tropical and temperate regions: Brateacoccus minor, Chlorella vulgaris, Trentepholia umbrina, Printzina effusa, Chroococcus lithophilus, C. pallidus, Asterocapsa divina, Gloeocapsa kuetzingigiana, G. rupestris, G. sanguiana, Gloeothece rupestris, Aphanothece pallida, Chroococcidiopsis kashayi, Cyanosarcina parthenonensis, Phormidium autumnale, Leptolyngbya fragilis, Nostoc commune, N. linckia, N. micropicum, N. punctiforme, Leptolyngbya boryana and Scytonema hoffman-bangii. Hence these results show a tropical diversity pattern of sub-aerial micro-algae and cyanobacteria in the Indian subcontinent quite different from other regions of the globe.

Occurrence of almost similar cyanobacteria taxa and the relative absence of green algal forms on the building facades of several localities in India, Brazil and Mexico under tropical conditions have been reported ealier (Table 3). On the contrary, in temperate regions, except for the sub-tropical and warm temperate zones of Spain and Italy, the algal forms occurring in similar habitats of Ukraine, France, Ireland, England and Denmark are 
Table 3. Comparative analysis of the occurrence of different genera of cyanobacteria and micro-algae on the exposed surfaces of buildings and monuments in various countries of the tropical and temperate regions of the globe

\begin{tabular}{|c|c|c|c|c|c|c|c|c|}
\hline \multirow[b]{2}{*}{ Class / Order/ Genus } & \multicolumn{3}{|c|}{ Tropical region } & \multicolumn{5}{|c|}{ Temperate region } \\
\hline & 1 India & 2 Brazil & 3 Mexico & 4 Ukraine & 5 Spain & 6 France & 7 Italy & $\begin{array}{c}8 \text { Ireland, } \\
\text { Denmark, } \\
\text { England }\end{array}$ \\
\hline \multicolumn{9}{|l|}{ Chlorophyta } \\
\hline \multicolumn{9}{|l|}{ Chlorococcales } \\
\hline Chlorococcum & + & - & - & + & + & - & + & - \\
\hline Actinochloris & - & - & - & - & - & - & - & + \\
\hline Sphaerochlamydella & - & - & - & + & - & - & - & - \\
\hline Nautococcus & - & - & - & - & + & - & - & - \\
\hline Tetracystis & - & - & - & + & + & - & - & - \\
\hline Hormotila & - & - & - & - & + & - & - & - \\
\hline Trebouxia & - & + & - & + & + & + & - & + \\
\hline Bracteacoccus & + & - & - & + & - & + & - & - \\
\hline Myrmecia & - & - & - & + & + & - & - & - \\
\hline Friedmannia & - & - & - & - & - & + & - & - \\
\hline Treubaria & - & - & - & - & - & - & - & - \\
\hline Dictyochloropsis & - & - & - & + & - & - & - & - \\
\hline Elliptochloris & - & - & - & + & - & - & - & - \\
\hline Dactyosphaerium & - & - & - & + & - & - & - & - \\
\hline Fottea & - & - & - & + & - & - & - & - \\
\hline Desmococcus & - & - & - & + & - & - & - & + \\
\hline Apatococcus & - & - & - & + & + & - & - & + \\
\hline Chlorosarcinopsis & - & - & - & + & + & - & - & - \\
\hline Ecdysichlamys & - & - & - & - & + & + & - & - \\
\hline Oocystis & - & + & - & - & + & + & - & - \\
\hline Germinella & - & - & - & + & - & - & - & - \\
\hline Gloeocystis & - & - & - & + & - & - & - & - \\
\hline Chlorokybus & - & - & - & - & - & + & - & - \\
\hline Neocystis & - & - & - & + & - & - & - & - \\
\hline Gloeotilopsis & - & - & - & + & - & - & - & - \\
\hline Muriella & - & - & - & - & + & + & - & - \\
\hline Coenochloris & + & - & - & - & - & - & - & - \\
\hline Chlorella & + & + & + & + & + & - & + & + \\
\hline Coccomyxa & - & - & - & + & - & - & - & - \\
\hline Pseudococcomyxa & - & - & - & + & - & - & - & - \\
\hline Scotiellopsis & - & - & - & + & - & - & - & - \\
\hline Leptosira & - & - & - & + & - & - & - & - \\
\hline Lobosphaeropsis & - & - & - & + & - & - & - & - \\
\hline Parietochloris & - & - & - & + & - & - & - & - \\
\hline Pleurastrum & - & - & - & + & - & - & - & - \\
\hline Radiococcus & + & - & - & - & - & - & - & - \\
\hline Scenedesmus & + & - & - & - & + & - & - & - \\
\hline Charophyta & - & - & - & - & - & - & - & - \\
\hline \multicolumn{9}{|l|}{ Klebsormidiales } \\
\hline Klebsormidium & - & - & - & + & + & + & + & + \\
\hline Stichococcus & - & - & - & + & + & + & - & + \\
\hline \multicolumn{9}{|l|}{ Prasiolales } \\
\hline Rosenvingiella & - & - & - & - & - & - & - & + \\
\hline Prasiola & - & - & - & - & - & - & - & + \\
\hline \multicolumn{9}{|l|}{ Ulotrichales } \\
\hline Ulothrix & - & - & - & - & + & - & + & - \\
\hline Cladophorales & & & & & & & & \\
\hline
\end{tabular}


Table 3. (continued)

\begin{tabular}{|c|c|c|c|c|c|c|c|c|}
\hline \multirow[b]{2}{*}{ Class / Order/ Genus } & \multicolumn{3}{|c|}{ Tropical region } & \multicolumn{5}{|c|}{ Temperate region } \\
\hline & 1 India & 2 Brazil & 3 Mexico & 4 Ukraine & 5 Spain & 6 France & 7 Italy & $\begin{array}{c}8 \text { Ireland, } \\
\text { Denmark, } \\
\text { England }\end{array}$ \\
\hline Cladophora & - & + & + & - & - & - & - & - \\
\hline \multicolumn{9}{|l|}{ Trentepohliales } \\
\hline Trentepohlia & + & + & - & - & + & + & + & - \\
\hline Printzina & - & - & - & - & - & - & - & + \\
\hline \multicolumn{9}{|l|}{ Conjugales } \\
\hline Cosmarium & + & - & - & - & + & - & - & - \\
\hline \multicolumn{9}{|l|}{ Bacillariophyceae } \\
\hline \multicolumn{9}{|l|}{ Pennales } \\
\hline Achnanthes & - & - & - & - & + & - & - & - \\
\hline Navicula & - & - & - & + & + & - & - & - \\
\hline Nitzschia & - & - & - & + & - & - & + & - \\
\hline Hantzschia & - & - & - & + & + & - & - & - \\
\hline Diadesmis & - & - & - & - & + & - & - & - \\
\hline \multicolumn{9}{|l|}{ Xanthophyta } \\
\hline \multicolumn{9}{|l|}{ Heterosiphonales } \\
\hline Botrydiopsis & - & - & - & + & + & - & - & - \\
\hline Eustigmatos & - & - & - & + & - & - & - & - \\
\hline Xanthonema & - & - & - & + & + & - & - & - \\
\hline Heteropedia & - & - & - & - & + & - & - & - \\
\hline Heterococcus & - & - & - & + & - & - & - & - \\
\hline \multicolumn{9}{|c|}{ Cyanophyta (Cyanobacteria) } \\
\hline \multicolumn{9}{|c|}{ Chroococcales } \\
\hline Chroococcus & + & + & - & - & + & + & + & + \\
\hline Gleocapsa & + & + & + & + & + & - & + & + \\
\hline Gloeothece & + & + & + & - & - & - & - & - \\
\hline Aphanocapsa & + & - & - & - & + & - & - & - \\
\hline Aphanothece & + & - & - & - & + & - & - & - \\
\hline Synechococcus & + & + & + & - & + & - & + & - \\
\hline Synechocystis & - & + & + & - & + & - & - & - \\
\hline Chlorogloeo & - & + & + & - & + & - & - & - \\
\hline Asterocapsa & + & - & - & - & + & - & - & - \\
\hline \multicolumn{9}{|l|}{ Chamaesiphonales } \\
\hline Chrococcidiopsis & + & + & + & - & + & + & + & - \\
\hline Cyanosarcina & + & - & - & - & - & + & - & - \\
\hline Cyanobacterium & - & - & - & - & + & - & - & - \\
\hline Chamaesiphon & - & - & - & - & + & + & - & - \\
\hline \multicolumn{9}{|l|}{ Pleurocapsales } \\
\hline Pseudocapsa & - & - & - & - & + & - & + & - \\
\hline Myxosarcina & + & + & + & - & - & - & + & - \\
\hline Pleurocapsa & + & + & + & - & + & - & - & - \\
\hline Xепососсиs & - & + & + & - & + & - & - & - \\
\hline Hyella & - & - & + & - & + & - & - & - \\
\hline Hydrococcus & - & - & + & - & - & - & - & - \\
\hline \multicolumn{9}{|l|}{ Nostocales } \\
\hline Oscillatoria & - & + & - & - & + & - & + & - \\
\hline Arthrospira & - & - & + & - & - & - & - & - \\
\hline Phormidium & + & + & + & + & + & + & + & + \\
\hline Pseudophormidium & - & - & - & - & + & + & - & - \\
\hline Lyngbya & + & + & + & + & - & - & - & - \\
\hline Leptolyngbya & + & + & + & - & + & + & + & - \\
\hline Schizothrix & + & - & - & - & + & - & - & - \\
\hline
\end{tabular}


Table 3. (continued)

\begin{tabular}{|c|c|c|c|c|c|c|c|c|}
\hline \multirow[b]{2}{*}{ Class / Order/ Genus } & \multicolumn{3}{|c|}{ Tropical region } & \multicolumn{5}{|c|}{ Temperate region } \\
\hline & 1 India & 2 Brazil & 3 Mexico & 4 Ukraine & 5 Spain & 6 France & 7 Italy & $\begin{array}{c}8 \text { Ireland, } \\
\text { Denmark, } \\
\text { England }\end{array}$ \\
\hline Symploca & - & - & - & + & + & - & + & - \\
\hline Microcoleus & + & + & - & - & + & + & + & - \\
\hline Anabaena & - & - & - & - & + & - & - & - \\
\hline Pseudoanabaena & - & - & - & - & + & - & - & - \\
\hline Nostoc & + & + & + & + & + & + & + & - \\
\hline Cylindrospermum & - & - & - & - & - & - & - & - \\
\hline Plectonema & + & + & + & - & - & - & + & - \\
\hline Scytonematopsis & - & + & - & - & - & - & - & - \\
\hline Scytonema & + & + & + & - & + & + & + & - \\
\hline Tolypothrix & + & + & - & - & + & - & - & - \\
\hline Calothrix & + & + & - & - & + & + & - & - \\
\hline \multicolumn{9}{|l|}{ Stigonematales } \\
\hline Mastigocladus & - & + & - & - & - & - & - & - \\
\hline Westiellopsis & + & - & - & - & - & - & - & - \\
\hline Fischerella & - & - & + & - & + & - & - & - \\
\hline Stigonema & + & - & - & - & + & - & - & - \\
\hline
\end{tabular}

1. Tripathi et al. (1991); 2. Crispim et al. (2004, 2006), Gaylarde and Gaylarde (2000); 3. Gaylarde et al. (2006), Ortega-Morales et al. (2005), Videla et al. (2000); 4. Darienko and Hoffmann (2003); 5. Aboal et al. (2003), Noguerol-Seoane and Rifón-Lastra (2003), OrtegaCalvo et al. (1993), Peraza Zurita et al. (2005), Uher et al. (2005); 6. Barberousse et al. (2006, 2007); 7. Rindi and López Bautista (2007), Tomaselli et al. (2000); 8. Crispim et al. (2003), Gaylarde and Gaylarde (2005), Rindi and Guiry (2004), Rindi et al. (2005).

principally green algae with cyanobacterial forms bring sparce. On the exteriors of the cathedral and buildings of Spain the cyanobacteria and green algae were almost equal in number, and both the groups of algae were dominant in the sub-aerial habitats of warm temperate locality. In addition, though the green algal genera Klebsormidium, Stichococcus and Trebouxia were dominant in the temperate regions, these did not occur on the exteriors of buildings of tropical countries. However, species of Gloeocapsa, Chroococcus, Chroococcidiopsis, Phormidium, Leptolyngbya, Nostoc, Scytonema, Chlorella and Trentepholia occurring in the sub-aerial habitats of temperate locations also colonize similar habitats in India and other tropical countries have a global occurrence. These findings are consistent with the few previous studies, in which green algae were shown to be dominant in temperate regions, whereas cyanobacteria dominant in the tropics, especially the forms with well developed sheaths and /or mucilage in their outer envelope. These differenences are based on the requirement for humidity and moderate light intensity on the part of green algae, and the capability to withstand high temperature, desiccation and protecting themselves from intense solar insolence on the part of cyanobacteria.

\section{ACKNOWLEDGEMENTS}

The authors thank the Ministry of Environment and Forests, Govt. of India for financial assistance through an All India Coordinated Project (AICOPTAX) on the Taxonomy of Algae. We also thank the Heads of the P. G. Departments of Botany and Biotechnology, Utkal University for providing laboratory facilities.

\section{REFERENCES}

Aboal M., Asencio A.D. and López-Jiménez E. 2003. Morphological, ultra structural and ecological study of Asterocapsa divina Komárek (Chroococcaceae, Cyanobacteria) from a cave of Southeastern Spain. Algolog. Stud. 109: 57-65.

Barberousse H., Tell G., Yéprémian C. and Couté A. 2006. Diversity of algae and cyanobacteria growing on buildings facades in France. Algolog. Stud. 120: 81-105.

Barberousse H., Rout B., Yéprémian C. and Boulon G. 2007. An assessment of facades coatings against colonization by aerial algae and cyanobacteria. Building Environ. 42: 2555-2561.

Branco C.C.Z. and Júnior O.N. 1996. Survey of stream macroalgae of eastern Atlantic rain forest of São Paulo State, South eastern Brazil. Algolog. Stud. 80: 35-57. 
Brehm U., Gorbushina A.A. and Motterhead D. 2005. The role of microorganisms and biofilms in the breakdown and dissolution of quartz and glass. Paleogeogr. Paleoclimat. Paleoecol. 219: 117-129.

Crispim C.A., Gaylarde P.M. and Gaylarde C.C. 2003. Algal and cyanobacteria biofilms on calcareous historic buildings. Curr. Microbiol. 46: 79-82.

Crispim C.A., Gaylarde C.C. and Gaylarde P.M. 2004. Biofilms on churchs walls in Porto Alegre, RS, Brazil, with special attention to cyanobacteria. Int. Biodeterior. Biodegrad. 54: 121-124.

Crispim C.A., Gaylarde P.M., Gaylarde C.C. and Neilan B.A. 2006. Deteriogenic cyanobacteria on historic buildings in Brazil detected by culture and molecular techniques. Int. Biodeterior. Biodegrad. 57: 239-243.

Desikachary T.V. 1959. Cyanophyta: Indian Council of Agricultural Research, New Delhi, 686 pp.

Darienko T. and Hoffmann L. 2003. Algal growth on cultural monuments in Ukraine. Biologia Bratislava 58: 575-587.

Gaylarde C.C. and Gaylarde P.M. 2005. A comparative study of the major microbial biomass of biofilms on exteriors of buildings in Europe and Latin America. Int. Biodeterior. Biodegrad. 55: 131-139.

Gaylarde C.C., Gaylarde P.M., Copp J. and Neilon B. 2004. Polyphasic detection of cyanobacteria in terrestrial biofilms. Biofouling 20: 71-79.

Gaylarde C.C. and Morton L.H.G. 1999. Deteriogenic biofilms on buildings and their control: a review. Biolfouling 14: 5974.

Gaylarde P.M, Englert G., Ortega-Morales O. and Gaylarde C.C. 2006. Lichen - like colonies of pure Trentepohlia on limestone monuments. Int. Biodeterior. Biodegrad. 58: 119-123.

Gaylarde P.M and Gaylarde C.C. 2000. Algae and cyanobacteria on painted buildings in Latin America. Int. Biodeterior. Biodegrad. 46: 93-97.

Gomez S.R., Johansen J.R. and Lowe R.L. 2003. Epilithic aerial algae of Great Smoky Mountains national park. Biologia, Bratislava 58: 603-615.

Hindák F. 1977. Studies on the Chlorococcal algae/ Chlorophyceae: VEDA. Publishing House of the Slovak Academy of Sceence, Bratislava, 186 pp.

Hrouzek P. and Šoun J. 2004. Some finds of subaerophytic cyanobacteria on wetted walls of La Palma (Canary islands). Czech Phycology Olomouc 4: 155-162.

Klochkova T.A. and Kim G.H. 2005. Ornamented resting spores of a green alga, Chlorella sp., collected from the stone standing Buddha statue at Jungnon Miruksazi in Korea. Algae 20: 295-298.

Komárek J. and Fott B. 1983. Das Phytoplankton des Süßwassers, 7. Teil: E. Schweizerbart' Sche Verlagsbuchhandlung. Stuttgart, $1001 \mathrm{pp}$.

Kovácik L. 2000. Cyanobacteria and algae as agents of biodeterioration of stone substrate of historical buildings and other cultural monuments. In: Choi S. and Suh M. (eds), Proceedings of the New Millennium International Forum on Conservation of Cultural Property, Daejeon, Korea. pp. 44-58.
Krishnamurthy V. 1998. Algae of India and neighbouring countries I. Chlorophycota, Oxford and IBH Publishing Co. Pvt. Ltd., New Delhi, 205 pp.

Mishra P.K. and Srivastava A.K. 2003. Some desmids (Chlorophyceae) from North - Eastern Uttara Pradesh, India. J. Ind. Bot. Soc. 82: 85-92.

Noguerol-Seoane A. and Rifón-Lastra A. 2003. Spatial and temporal distribution of Cyanoprokaryota in edified granite walls. Taxonomical consideration. Algolog. Stud. 109: 443454.

Ortega - Calvo J.J., Sanchez-Castillo P.M. and HernandezMarine M. 1993. Isolation and characterization of epilithic chlorophytes and cyanobacteria from two Spanish cathedrals (Salamanca and Toledo). Nova Hedwigia 57: 239-253.

Ortega - Morales B.O., Gaylarde C.C., Englert G.E. and Gaylarde P.M. 2005. Analysis of salt - containing biofilms on limestone buildings of the Mayan culture at Edzna, Mexico. Geomicrobiol. J. 22: 261-268.

Pattanaik B. and Adhikary S.P. 2002. Blue-green algal flora at some archaeological sites and monuments of India. Feddes Repertor. 113: 289-300.

Peraza Zurita Y., Cultrone G., Sânchez-Castillo P., Sebastiân E. and Bolivar F. C. 2005: Microalgae association with deteriorated stone work of the fountain of Bibatauin in Granada, Spain. Int. Biodeterior. Biodegrad. 55: 55-61.

Philipose M.T. 1967. Chlorococcales: Indian Council of Agricultural Research, New Delhi, 345 pp.

Rindi F. and Guiry M.D. 2004. Composition and spatial variability of terrestrial algal assemblages occurring at the base of urban walls in Europe. Phycologia 43: 225-235.

Rindi F and López-Bautista J.M. 2007. New and interesting records of Trentepohlia (Trentepohliales, Chlorophyta) from French Guiana, including the description of two new species. Phycologia 46: 698-708.

Rindi F., Sherwood A.R. and Guiry M.D. 2005. Taxonomy and distribution of Trentepohlia and Printzina (Trentepohliales, Chlorophyta) in the Hawaiian Islands. Phycologia 44: 270284.

Rippka R. Deruelles J, Waterbury J.B, Herdman M and Stanier R.Y. 1979. Generic assignments, strain histories and properties of pure cultures of cyanobacteria. J. Gen. Microbiol. 111: $1-61$.

Thompson R.H. 1959. Fresh Water Biology. In: Edmondson W.T. (ed.), Algae. Chapman and Hall Ltd., London. pp. 115168.

Tilden J. 1910. Minnesota Algae: Vol. l. The Myxophyceae of North America and adjacent regions including Centeral America, Greenland, Bermuda, West Indies and Hawaii. The University of Minnesota, Minneapolis, Minnesota, USA, 328 pp.

Tomaselli L., Lamenti G., Bosco M. and Tiano P. 2000. Biodiversity of photosynthetic micro - organisms dwelling on stone monuments. Int. Biodeterior. Biodegrad. 46: 251-258.

Tripathi S.N. 1984. Observation on subaerial blue-green algae from the campus of the Banaras Hindu University, Varanasi - 1. J. Sci. Res. 34: 179-185.

Tripathi S.N., Tiwari B.S. and Talpasayi E.R.S. 1991. Growth of 
cyanobacteria (blue green algae) on urban buildings. Energy Build. 15-16: 499-505.

Tripathy P., Roy A., Anand N. and Adhikary S.P. 1999. Blue green algal flora from the temples and monuments of India. Feddes Repertor. 110: 133-144.

Uher B., Aboal M. and Kovácik L. 2005. Epilithic and chasmoendolithic phycoflora of monuments and buildings in southeastern Spain. Cryptogamie Algologie 26: 275-358.
Videla H.A., Guiamet P.S. and Gomez de Saravia S.G. 2000. Bioterioration of Mayan archaeological sites in the Yucatan Peninsula, Mexico. Int. Biodeterior. Biodegrad. 46: 335-341.

West W. and West G.S. 1905. A Monograph of the British Desmidiaceae. The Ray Society, London, 204 pp.

Received 4 April 2008

Accepted 3 May 2008 